This is the pre-print version of the paper (Accepted Date:27 October 2019).

Please cite this article as:

Alongi A, Angelotti A, Mazzarella L, Experimental validation of a steady periodic analytical model for Breathing Walls, Building and Environment (2019), doi: https://doi.org/10.1016/j.buildenv.2019.106509 


\title{
Experimental validation of a steady periodic analytical model for Breathing Walls
}

\author{
A. Alongi ${ }^{\mathrm{a}}$, A. Angelotti ${ }^{\mathrm{a}, *}$, L. Mazzarella ${ }^{\mathrm{a}}$ \\ ${ }^{a}$ Politecnico di Milano, Department of Energy, Via Lambruschini, 4 (20156) Milano, Italy
}

\begin{abstract}
The Breathing Wall behavior under variable boundary conditions is described by an analytical model based on a one-dimensional porous domain crossed by air and subject to third type steady periodic boundary conditions. To the best of the authors' knowledge, its experimental validation is not provided in literature.

In this work, a new model is derived considering Dirichlet steady periodic boundary conditions. The model is experimentally validated testing a $1 \mathrm{~m}^{2}$ no-fines concrete sample in the Dual Air Vented Thermal Box apparatus, specially improved to replicate dynamic thermal conditions. The experiments show that increasing the air flow velocity across the Breathing Wall from 0 to $12 \mathrm{~mm} / \mathrm{s}$ enhances thermal coupling between the two environments, namely reduces the wall thermal capacity, with a decrease in the penetration time from $4.3 h$ to $3 h$.

The model shows a very good agreement with experimental data when predicting temperature distribution across the domain, with error averages and standard deviations within the thermocouple accuracy after calibration, assumed to be $0.15^{\circ} \mathrm{C}$. The lesser yet good agreement concerning conduction heat flux density is explained in terms of accuracy in the measurement of the boundary conditions and critical issues in the heat flow measure itself (i.e. probe thermal resistance, thermal contact, emissivity mismatch).
\end{abstract}

Keywords: Dynamic insulation, Breathing wall, Air permeable materials, Energy efficiency, Analytical modeling, Steady periodic conditions, Experimental validation, Laboratory setup

\section{Introduction}

Due to the compelling environmental and energy challenges, in the past decades a great research effort has been focused on reducing the buildings impact on the environment, following the introduction of stringent energy efficiency targets through the Directive on Energy Performance of Buildings EPBD 2002/91/EU and 2010/31/EU [1, 2]. These documents also state that a significant role in energy demand (35-40\%) and pollutant emissions in the European Union is played by the building stock.

Even though the attention has been at first focused on the reduction of energy needs for space heating, the rise of consumptions for summer cooling, as a consequence of global warming, has led in recent years to a more complex approach at building design, with the introduction of new technologies able to mitigate the en-

\footnotetext{
${ }^{*}$ Corresponding author. Tel. 022399 5183; Fax. 0223993913

Email address: adriana.angelotti@polimi.it (A. Angelotti)
}

Preprint submitted to Building and Environment ergy demand during the whole year [3]. Superinsulation might provide a solution whenever the energy balance is dominated by the indoor-outdoor temperature difference. Conversely, it can become detrimental when the envelope needs to effectively dispose of internal or solar loads: even though undesired heat can be released through stack ventilation or nocturnal free-cooling, this strategy requires windows' opening, which might not be possible for any reason.

In this regard, a promising path is represented by the Dynamic Insulation materials and systems, in which the wall thermal transmittance is somehow controllable and tunable. It was demonstrated [4-6] that the ability to actively modulate the heat transferred through the envelope to meet the instantaneous requirements can improve the overall building behaviour.

The so called Breathing Walls (BW) are a special kind of Dynamic Insulation system, also referred to as permeodynamic insulation [7], in which air permeable layers are crossed by the airflow required to provide the necessary room airchange. In this way, a significant 


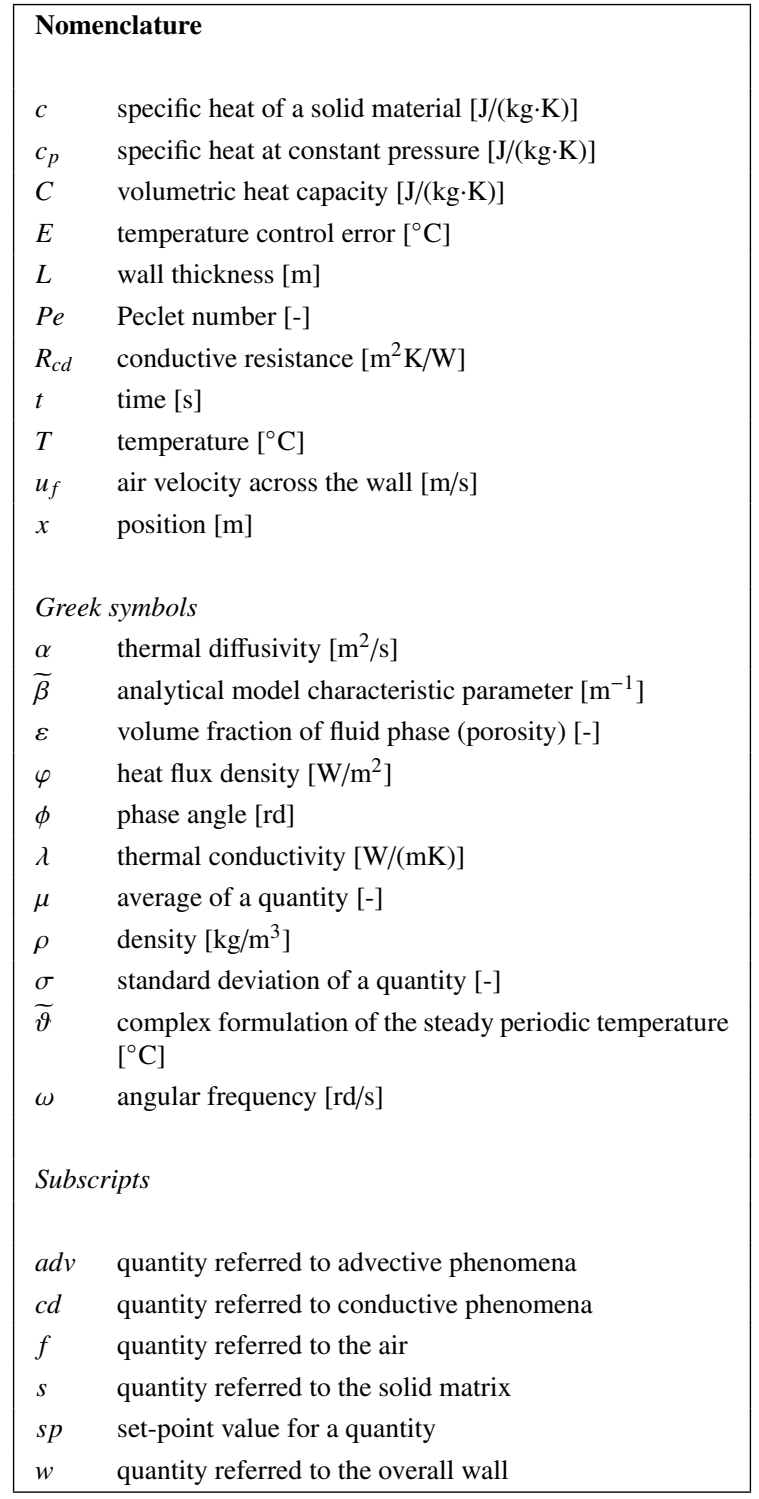

portion of the envelope is integrated into the ventilation plant as heat recovering unit and filter [8]. Moreover, the air motion through the solid matrix of the air permeable layers inside the walls allows either to reduce or to increase the thermal coupling between indoor and outdoor environments. In the first case, heat flux and airflow move in opposite direction (contra flux), while they move in the same direction in the second case (pro flux).

Traditionally, since this technology was initially studied in heating dominated regions [9, 10], the research effort has been focused on contra-flux application in steady state boundary conditions, because of its ability to reduce conduction heat losses and mitigate the en- ergy needs related to ventilation. Overall, it was demonstrated how this technical solution is able to recover part of the conductive heat losses by pre-heating the fresh air coming from outside, so that the Breathing Wall can be seen as a recovery heat exchanger whose efficiency depends on the air flow velocity [11]. Moreover, in winter contra-flux steady state condition it was demonstrated both analytically [8] and experimentally [12, 13] that the heat exchange at pore scale leads to an exponential trend of the temperature distribution and to the cooling of the inner surface [14, 15]. Since the air crosses inward the solid matrix at very low speed, the permeable layer acts also as high efficiency filter for PM2-10 [16]. Another interesting application of Breathing Walls as a diffused heating device is presented in [17]. Finally, in cooling dominated conditions, some Authors suggest that the porous wall can act as Exhaust Air Insulation [18], where the cold indoor air is expelled through the envelope to partially dispose of the internal energy accumulated by the structures.

As far as pro-flux is concerned, since it promotes heat exchange between spaces separated by Breathing Walls, it becomes relevant in summer conditions. Being summer outdoor conditions (i.e. temperature and solar radiation) inherently variable in time, conductive heat flux typically switches direction during the day. Therefore, if the airflow direction is kept constant all day long, during a typical summer day an alternation occurs between pro and contra-flux operation, as reported in [19]. Hence, there are a few works in literature solely focused on pro-flux. An example is given in [20], where the effects of expelling the ventilation air through the permeable wall during the night in the cooling season are investigated numerically. In [21] a coupled pro-flux and contra-flux operation is proposed: two neighbor test rooms are provided with a Breathing Wall each. The ventilation air is supplied through the BW in the first room, is drawn by a fan to the second room and then is exhausted through the second BW. The airflow is alternated every 15 minutes in order to store heat and moisture. It is found that the BW system has a recovery efficiency of almost $90 \%$ for exhaust air heat and between 22 and $30 \%$ for heat lost in conduction.

As far as modeling of BW is concerned, a onedimensional analytical model for heat transfer in steady state was proposed in the 90's under first type [8] and third type [22] boundary conditions. Such model was recently experimentally validated in laboratory, although the opportunity to consider a velocity distribution of the inlet air was observed [12]. Modeling BW in transient state has mainly been approached numerically through finite difference methods [20, 23], even includ- 
ing the effect of the air gap channel between the porous layer and the external cladding [18]. Numerical models are the most appropriate for yearly simulations of the BW operation in buildings under realistic climatic and indoor conditions. To this purpose, the integration into common Building Energy Simulation tools is advisable. However, analytical models generally allow a deeper insight into the physics of the system and can be used as a reliable reference to validate numerical models. Moreover, the definition of well-known dynamic properties of building components, such as periodic thermal transmittance and admittance [24], is based on the analytical solution of the steady periodic Dirichlet problem, as demonstrated in [25]. In a fundamental work by Krarti [26], an analytical model for a BW in steady periodic regime under third type boundary conditions was developed. To the best of the Authors' knowledge such model has not been experimentally validated yet, which is the main contribution of the present paper. In order to provide an experimental validation, the dynamic heat transfer problem presented in [26] is here reconsidered through the application of first-type boundary conditions and a new solution is found. Assuming temperature boundary conditions instead of convective-radiative heat flow ones is preferable, since according to [17] at the BW surfaces a complex mixed convection mode occurs, along with radiative heat exchange. Such convection mode is the result of the interaction between the forced air flow across the porous medium and the natural convection flow at the room scale in each environment. Therefore, further efforts are necessary to derive correlations to accurately evaluate the convective coefficient on the surface of all kinds of porous materials used in BW.

The experimental validation of the steady periodic analytical model reported in this paper is performed on a BW sample tested in the Dual Air Vented Thermal Box. The laboratory rig, firstly presented in [12, 13], has been specially improved in order to reproduce dynamic boundary conditions. The performance of the apparatus and the results of the comparison between the measurements and the model calculations are presented and discussed in the paper.

\section{Mathematical model}

A Breathing Wall component, as represented in Figure 1. can be investigated through a mathematical model based on the following hypotheses:

1. indefinitely extended single-layer construction;

2. one-dimensional heat transfer problem;

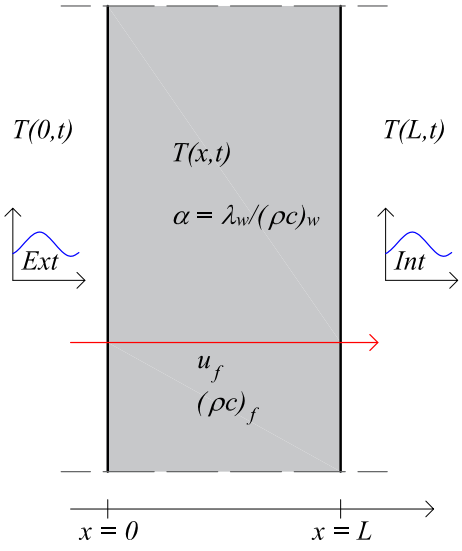

Figure 1: Simplified representation of a Breathing Wall.

3. generic isotropic, homogeneous and air permeable material;

4. material properties and air velocity are constant and not dependent on temperature.

As shown in Figure 1, the spatial coordinate $x$ is directed from the outer (left) to the inner (right) surface, therefore both airflow velocity and heat flux density are considered positive when directed inward. Variable Dirichlet boundary conditions are considered: temperatures are imposed at the outer and the inner edges of the domain, being $T(0, t)=T_{0}(t)$ and $T(L, t)=T_{L}(t)$ respectively, and can both be decomposed into a steady-state and a steady-periodic component, the latter fluctuating as a sine or cosine function in a $24 \mathrm{~h}$ period. Moreover, it is also introduced the hypothesis of

\section{5. local thermal equilibrium,}

as defined in [27] and implied in [8, 22, 23, 26, 28]. Namely, this simplification can be introduced whenever the temperature difference between the solid and the fluid phase at pore level is negligible. Therefore, no distinction between solid matrix and fluid sub-domain from the macroscopic point of view is considered. Being interested in the steady periodic solution, the initial condition can be omitted. Under these hypotheses, the heat transfer problem is expressed as:

$$
\left\{\begin{array}{l}
(\rho c)_{w} \frac{\partial T}{\partial t}+u_{f}\left(\rho c_{p}\right)_{f} \frac{\partial T}{\partial x}=\lambda_{w} \frac{\partial^{2} T}{\partial x^{2}} \\
T(0, t)=T_{0}(t)=\bar{T}_{0}+\Delta T_{0} \cdot \cos \left(\omega t+\phi_{0}\right) \\
T(L, t)=T_{L}(t)=\bar{T}_{L}+\Delta T_{L} \cdot \cos \left(\omega t+\phi_{L}\right)
\end{array}\right.
$$


where $T$ is the temperature distribution, $u_{f}$ is the airflow velocity across the wall (i.e. Darcy velocity, supposed constant in space and time), $\lambda, \rho$ and $c$ are the thermal conductivity, the density and the specific heat (at constant pressure when related to a gas) respectively, referred to the overall porous material ( $w$ subscript) or the air only ( $f$ subscript). The quantities referred to the porous material are defined as the volume averages of the corresponding solid and fluid phase ones. As far as the boundary conditions are concerned, $\bar{T}$ is the average (steady-state) component, while $\Delta T$ is the amplitude of the temperature fluctuation (defined by the angular frequency $\omega$ and the phase angle $\phi$ ). Since the boundary conditions are periodic and their evolution over time is known, it is possible to hypothesize that the solution itself will be:

$$
\begin{aligned}
T(x, t)=\underbrace{\bar{T}(x)}_{\text {steady-state }} & +\underbrace{\widetilde{T}(x, t)}_{\text {steady-periodic }}= \\
& =\bar{T}(x)+\Delta T(x) \cdot \cos (\omega t+\phi)
\end{aligned}
$$

By applying the superposition principle of the linear differential problems, as demonstrated in [25], the heat transfer problem in Eq. (1) can be decomposed into a steady-state and a steady-periodic problem, that will be solved separately.

\subsection{Steady-state problem}

The steady-state component of the heat transfer problem described in Eq. (1) is:

$$
\left\{\begin{array}{l}
u_{f}\left(\rho c_{p}\right)_{f} \frac{d \bar{T}}{d x}=\lambda_{w} \frac{d^{2} \bar{T}}{d x^{2}} \\
\bar{T}(0)=\bar{T}_{0} \\
\bar{T}(L)=\bar{T}_{L}
\end{array}\right.
$$

that leads to the solution:

$$
\bar{T}(x)=\frac{e^{\frac{P e}{L} x}-1}{e^{P e}-1}\left(\bar{T}_{L}-\bar{T}_{0}\right)+\bar{T}_{0}
$$

where $P e$ is the Peclet number defined as:

$$
P e=\frac{u_{f}\left(\rho c_{p}\right)_{f} L}{\lambda_{w}}
$$

The steady-state solution was already presented in past works [8, 26] and experimentally validated in [12, 13]. Starting from Eq. (4) it is possible to obtain both the conductive and the advective components of the heat flux density $\left(\bar{\varphi}_{c d}\right.$ and $\bar{\varphi}_{a d v}$ respectively):

$$
\begin{gathered}
\bar{\varphi}_{c d}(x)=-\lambda_{w} \frac{d \bar{T}(x)}{d x}=-\frac{P e}{R_{c d}} \frac{e^{\frac{P e}{L} x}}{e^{P e}-1}\left(\bar{T}_{L}-\bar{T}_{0}\right) \\
\bar{\varphi}_{a d v}(x)=\left.\dot{m} c_{p, f} \Delta \bar{T}\right|_{0} ^{L}=\frac{P e}{R_{c d}}\left[\frac{e^{\frac{P e}{L} x}-1}{e^{P e}-1}\left(\bar{T}_{L}-\bar{T}_{0}\right)\right]
\end{gathered}
$$

where $R_{c d}$ is the conductive resistance of the Breathing Wall, defined as the ratio between its thickness $L$ and the thermal conductivity of the porous material $\lambda_{w}$, and $\dot{m}$ is the air mass flow rate per unit surface.

Since the steady-state behaviour of Breathing Walls has already been thoroughly discussed in the past [8, 12, 13], no further investigation will be presented in this paper.

\subsection{Steady-periodic problem}

The time-dependent component of the heat transfer problem described in Eq. (1) is:

$$
\left\{\begin{array}{l}
(\rho c)_{w} \frac{\partial \widetilde{T}}{\partial t}+u_{f}\left(\rho c_{p}\right)_{f} \frac{\partial \widetilde{T}}{\partial x}=\lambda_{w} \frac{\partial^{2} \widetilde{T}}{\partial x^{2}} \\
\widetilde{T}(0, t)=\widetilde{T}_{0}(t)=\Delta T_{0} \cdot \cos \left(\omega t+\phi_{0}\right) \\
\widetilde{T}(L, t)=\widetilde{T}_{L}(t)=\Delta T_{L} \cdot \cos \left(\omega t+\phi_{L}\right)
\end{array}\right.
$$

Due to the periodic nature of both the boundary conditions and the solution, it is convenient to represent them as real part of proper complex numbers i.e.:

$$
\begin{aligned}
& \widetilde{T}_{0}(t)=\Delta T_{0} \cdot \cos \left(\omega t+\phi_{0}\right)=\mathfrak{R}[\widetilde{\vartheta}(0, t)] \\
& \text { where } \widetilde{\vartheta}(0, t)=\left(\Delta T_{0} e^{i \phi_{0}}\right) e^{i \omega t}=\vartheta_{0} e^{i \omega t}
\end{aligned}
$$

$$
\begin{gathered}
\widetilde{T}_{L}(t)=\Delta T_{L} \cdot \cos \left(\omega t+\phi_{L}\right)=\mathfrak{R}[\widetilde{\vartheta}(L, t)] \\
\text { where } \widetilde{\vartheta}(L, t)=\left(\Delta T_{L} e^{i \phi_{L}}\right) e^{i \omega t}=\vartheta_{L} e^{i \omega t}
\end{gathered}
$$

$$
\begin{aligned}
& \widetilde{T}=\Delta T(x) \cdot \cos (\omega t+\phi)=\mathfrak{R}[\widetilde{\vartheta}(x, t)] \\
& \text { where } \widetilde{\vartheta}(x, t)=\left(\Delta T e^{i \phi}\right) e^{i \omega t}=\widetilde{\vartheta}(x) e^{i \omega t}
\end{aligned}
$$

Subsequently, the time and space derivatives of the complex solution $\widetilde{\vartheta}(x, t)$ become:

$$
\frac{\partial \widetilde{\vartheta}(x, t)}{\partial t}=i \omega e^{i \omega t} \widetilde{\vartheta}(x)
$$




$$
\begin{gathered}
\frac{\partial \widetilde{\vartheta}(x, t)}{\partial x}=e^{i \omega t} \frac{\partial \widetilde{\vartheta}(x)}{\partial x} \\
\frac{\partial^{2} \widetilde{\vartheta}(x, t)}{\partial x^{2}}=e^{i \omega t} \frac{\partial^{2} \widetilde{\vartheta}(x)}{\partial x^{2}}
\end{gathered}
$$

Therefore, the heat transfer problem in Eq. (8) becomes:

$$
\left\{\begin{array}{l}
\frac{d^{2} \widetilde{\vartheta}(x)}{d x^{2}}-\frac{P e}{L} \frac{d \widetilde{\vartheta}(x)}{d x}-\frac{i \omega}{\alpha_{w}} \widetilde{\vartheta}(x)=0 \\
\widetilde{\vartheta}(0)=\Delta T_{0} e^{i \phi_{0}}=\widetilde{\vartheta}_{0} \\
\widetilde{\vartheta}(L)=\Delta T_{L} e^{i \phi_{L}}=\widetilde{\vartheta}_{L}
\end{array}\right.
$$

where it is possible to observe that the time variable has been eliminated, since it only appears in the $e^{i \omega t}$ factor in Eq. (12), (13) and (14). The solution of this problem is:

$$
\widetilde{\vartheta}(x)=e^{\frac{P_{e}}{2} \frac{x}{L}} \frac{\sinh [\widetilde{\beta}(L-x)]}{\sinh (\widetilde{\beta} L)} \widetilde{\vartheta}_{0}+e^{\frac{P e}{2}\left(\frac{x}{L}-1\right)} \frac{\sinh (\widetilde{\beta} x)}{\sinh (\widetilde{\beta} L)} \widetilde{\vartheta}_{L}
$$

where the $\widetilde{\beta}\left[\mathrm{m}^{-1}\right]$ coefficient is defined as:

$$
\widetilde{\beta}=\sqrt{\frac{P e^{2}}{4 L^{2}}+\frac{i \omega}{\alpha_{w}}} \text { with } \alpha_{w}=\frac{\lambda_{w}}{(c \rho)_{w}}
$$

Like what has been reported for the steady-state component of the problem, it is now possible to obtain the conductive and the advective heat flux density $\widetilde{\varphi}_{c d}$ and $\widetilde{\varphi}_{a d v}$ respectively), using Eq. (16):

$$
\begin{gathered}
\widetilde{\varphi}(x)_{c d}= \\
-\lambda_{w} e^{\frac{P e}{2} \frac{x}{L}}\left\{\frac{P e}{2 L} \frac{\sinh [\widetilde{\beta}(L-x)]}{\sinh (\widetilde{\beta} L)}-\widetilde{\beta} \frac{\cosh [\widetilde{\beta}(L-x)]}{\sinh (\widetilde{\beta} L)}\right\} \widetilde{\vartheta}_{0}+ \\
-\lambda_{w} e^{\frac{P e}{2}\left(\frac{x}{L}-1\right)}\left[\frac{P e}{2 L} \frac{\sinh (\widetilde{\beta} x)}{\sinh (\widetilde{\beta} L)}+\widetilde{\beta} \frac{\cosh (\widetilde{\beta} x)}{\sinh (\widetilde{\beta} L)}\right] \widetilde{\vartheta}_{L} \\
\widetilde{\varphi}_{a d v}(x)=\frac{P e}{R_{c d}}\left[e^{\frac{P e}{2} \frac{x}{L}} \frac{\sinh [\widetilde{\beta}(L-x)]}{\sinh (\widetilde{\beta} L)}-1\right] \widetilde{\vartheta}_{0}+ \\
\quad+\frac{P e}{R_{c d}} e^{\frac{P e}{2}\left(\frac{x}{L}-1\right)} \frac{\sinh (\widetilde{\beta} x)}{\sinh (\widetilde{\beta} L)} \widetilde{\vartheta}_{L}
\end{gathered}
$$

In Appendix A, Eq. (16) and (18) are manipulated in order to put in evidence the real and imaginary parts of the complex numbers. At this point the solutions of both the steady-state and the steady-periodic components are available and can be combined using Eq. (2). A similar approach gives the conductive heat flux as the sum of the steady-state and the steady periodic components. The experimental validation of this analytical model has been performed using the DAVTB apparatus described in [12, 13] and is presented later in this work.

\section{Experimental setup}

In this section, the whole experimental setup is discussed. The main features of the facility are provided, then the improvements introduced into the control algorithm in order to reproduce a dynamic regime are described. Finally, the thermo-physical and geometrical properties of the Breathing Wall sample investigated in this work are illustrated.

\subsection{The DAVTB facility}

The laboratory rig used for this work is the Dual Air Vented Thermal Box (DAVTB [12, 29]) developed in the Building Physics Laboratory of the Energy Department of Politecnico di Milano (Figure 2(a)). It was designed to test building envelope components under desired thermal boundary conditions, with the potential to impose a controlled airflow across the sample, if it operates as a Breathing Wall (Figure 2(b)).

The DAVTB apparatus consists of two insulated cubic chambers, whose net volume is around $1.9 \mathrm{~m}^{3}$ each, with a metal frame in between used as sample housing. Due to the dimensions of the frame, it is possible to test walls with a frontal area of around $1 \mathrm{~m}^{2}$ and a thickness up to $0.3 \mathrm{~m}$, which is considered as the upper limit in order to neglect any edge effect in the central part of the sample.

The setup is provided with an air recirculation plant that connects the chambers, allowing a controlled airflow to cross the sample with the desired speed and direction. Moreover, each box can be thermally controlled using radiant panels (visible in Figure 2(b) connected in parallel to the hydronic plant (Figure 2(a) that provides water at the desired temperature to either heat or cool the air inside each box. At the same time, thermally controlled water is provided to a heat exchanger connected to the air recirculation plant. Due to this design, operative temperature can be controlled in each chamber separately to reproduce the desired conditions. Both steady and unsteady state conditions can be achieved: while the reliability of first have been thoroughly discussed in previous works [12, 13], the stability of the 


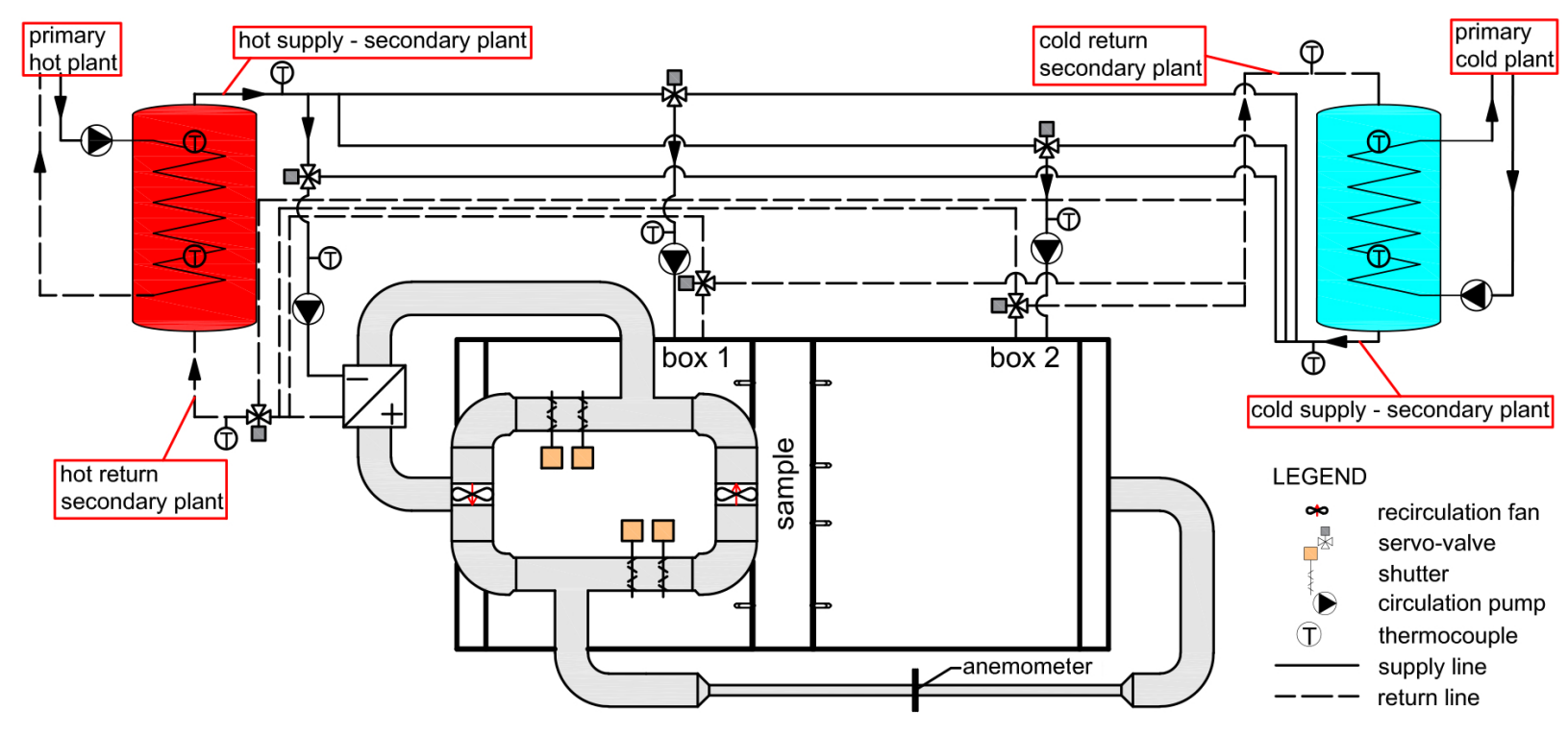

(a)

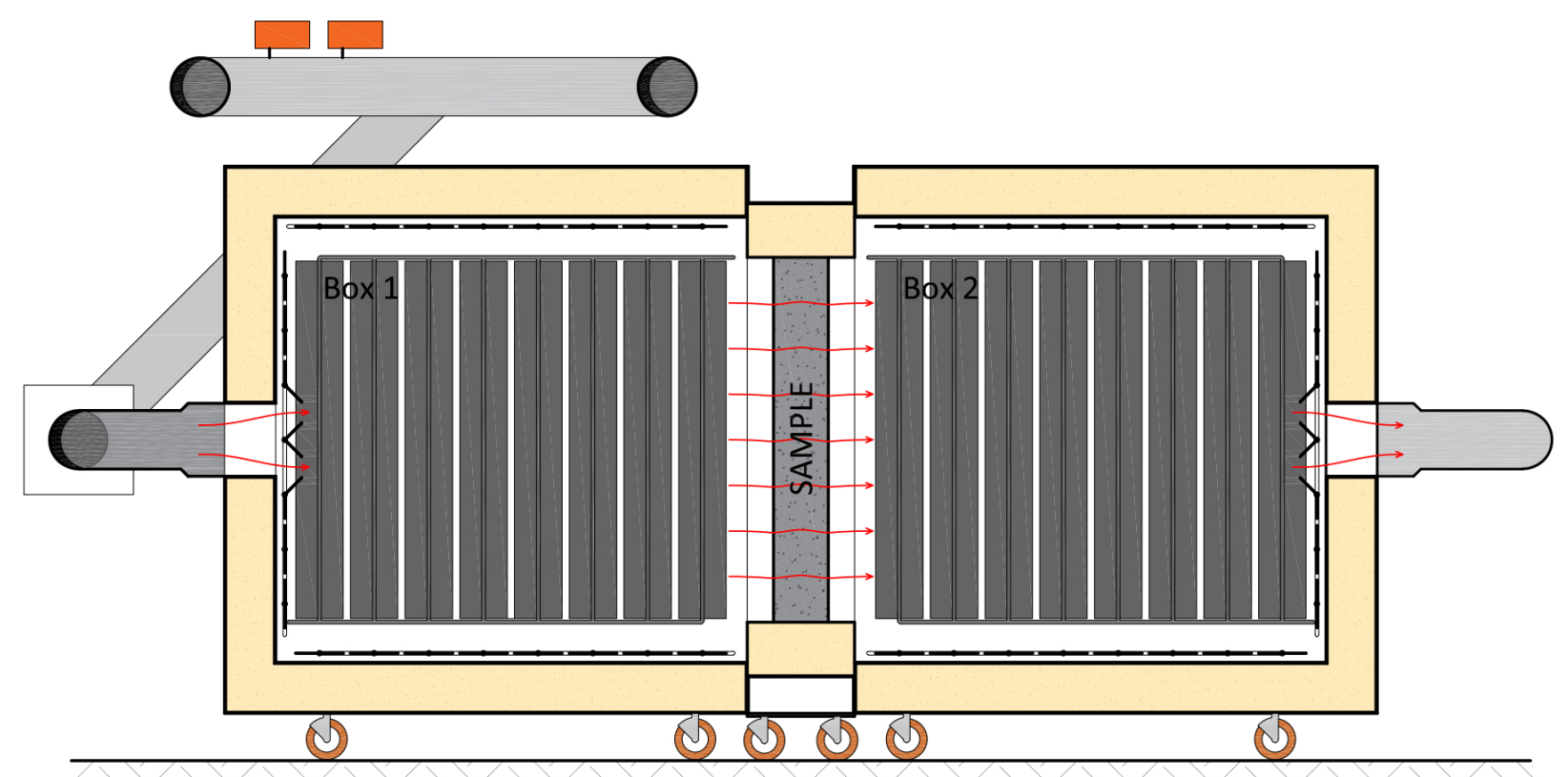

(b)

Figure 2: (a) Layout of the whole apparatus, with both the hydronic plant and the air recirculation system represented [12]. (b) Vertical section of the chambers (Box 1 and Box2) with the Breathing Wall sample in between. The airflow direction considered in this work is also included.

second is one of the goals of this paper, since the control algorithm had to be developed further in order to perform this task.

The setup is provided with calibrated T-type thermocouples to measure air and operative temperature inside each chamber, along with water temperature in several points inside the hydronic plant. Moreover, a bidirectional fan anemometer is installed to evaluate the average airflow velocity across the Breathing Wall investigated. Data are collected every $5 \mathrm{~s}$ with an Agilent 


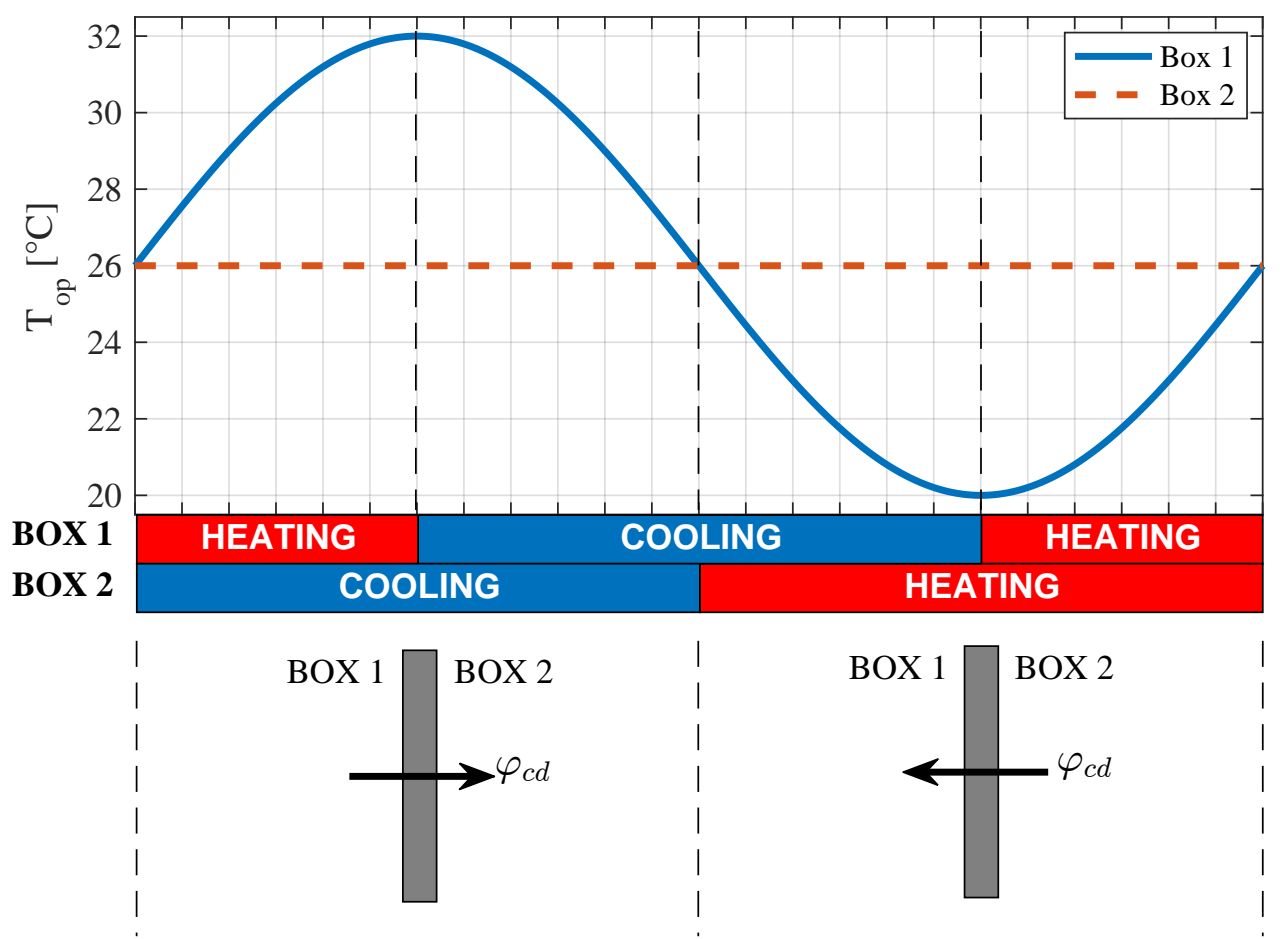

Figure 3: Representation of the operative temperature set points in Box 1 (sinusoidal) and Box 2 (constant). The active working mode at any time for each chamber is also represented, along with the conductive heat flux density direction through the sample in simplified conditions (i.e. neglected sample heat capacity).

34980A multifunctional switch unit. Further details are given in [12, 13].

As far as the airflow is concerned, with the sample investigated in this work, the recirculation plant allows to achieve specific airflow rates in the $0 \div 0.013 \mathrm{~m}^{3} /\left(\mathrm{m}^{2} \cdot \mathrm{s}\right)$ range in both directions, thanks to manual control of the butterfly dumpers and the fan rotational velocity. These values correctly represent the Breathing Wall working conditions [8, 30].

\subsection{The control algorithm}

The thermal control is based on a mixed proportional$\mathrm{ON} / \mathrm{OFF}$ approach. Once the operative temperature set point and the difference between this quantity and the water supply temperature are defined by the user, the proportional $(\mathrm{P})$ controller acts on the mixing valves to achieve the desired supply temperature, while the $\mathrm{ON} / \mathrm{OFF}$ controller tracks the operative temperature in each chamber separately. As it was shown in [12], this algorithm gives good results in reproducing a $15{ }^{\circ} \mathrm{C}$ $40{ }^{\circ} \mathrm{C}$ steady state condition with specific airflow rates from 0 to $0.012 \mathrm{~m}^{3} /\left(\mathrm{m}^{2} \cdot \mathrm{s}\right)$, achieving an average control error from $0{ }^{\circ} \mathrm{C}$ to $0.06{ }^{\circ} \mathrm{C}$, with a standard deviation from $0.05{ }^{\circ} \mathrm{C}$ to $0.09{ }^{\circ} \mathrm{C}$.

Even though the P-ON/OFF approach was maintained, the following changes were implemented in order to reproduce periodic thermal fluctuations: first of all, a sine-shaped operative temperature set-point was added, allowing the user to define the average value, the fluctuation amplitude and period ( $24 \mathrm{~h}$ for the purpose of this work). Then, the supply water temperature is defined by the user to manage the most critical conditions (i.e. at the top and the bottom of the thermal fluctuation). However, due to the heat transfer through the wall and its thermal capacity, the control algorithm must be able to switch the working model (from heating to cooling and back) according to the needs. A simplified representation of this behaviour is provided in Figure 3. It shows a time dependent temperature setpoints in one chamber and a constant one in the other, the working regime for each chamber and the direction of the conductive heat flux through the sample. It is important to notice that it consists of an ideal representation, disregarding the influence of both laboratory room 
conditions (i.e. air temperature) and wall sample thermal capacity.

Going more in detail, this algorithm tracks for each chamber both the ON/OFF switching for its circulation pump and the instantaneous deviation between the measured operative temperature and its set point. A time counter starts when the pump is turned off: if the operative temperature differs from its desired value for more than $0.1^{\circ} \mathrm{C}$ after a user defined time interval (1800 seconds in this work), the working mode is changed. Furthermore, the sign of the temperature error is taken into consideration: for instance, if the radiant panels are working in heating mode only a negative error (measured value greater than set-point) might allow a switch, while the positive one is only relevant if the cooling regime is active. Finally, since the thermal load for each chamber after every switch is supposed to be low, the absolute difference between the desired supply water and the chamber operative temperature is linearly increased form $0{ }^{\circ} \mathrm{C}$ to the user defined value during a time interval of 5 minutes. The effectiveness of this approach is discussed in Section 5.1.

\subsection{The no-fines concrete sample}

Dealing now with the sample investigated, it consists of the $15 \mathrm{~cm}$ thick no-fines concrete [31] wall already described in detail in [12, 13] and shown in Figure 4(a) It is divided into nine $32 \mathrm{~cm} \times 32 \mathrm{~cm}$ blocks, five of which named A to E are provided with 11 T-type thermocouples each, to measure the temperature distributions across their section. For this work, a heat flow meter was added on the surface of block $\mathrm{C}$ facing toward Box 2 (Figure 4(b)). It consists of a $4.4 \mathrm{~mm} \times 4.4 \mathrm{~mm}$ gSKIN $®$ sensor produced by greenTEG, with a nominal accuracy equal to $5 \%$. It is located on a solid flat spot in the very center of the block, so that it measures the conductive component of the heat flux, without sensing the advective one.

The material is a concrete-based mixture that includes aggregates with an average diameter $\phi$ from $6 \mathrm{~mm}$ to $12 \mathrm{~mm}$. The chosen mix design [12, 13] leads to a porous solid matrix with highly interconnected pores. Thermo-physical properties were measured and assessed in various ways: first of all, the porosity $\varepsilon$ was measured using the Archimedes method [31] and the result is $\varepsilon=(30 \pm 2) \%$. Then, using 8 compact samples with the same mix-design of the Breathing Wall but based on fine aggregates ( $\phi$ up to $2 \mathrm{~mm}$ ), the density of the solid matrix was derived through mass and volume measurements, obtaining $\rho_{s}$ equal to $(2483 \pm 87) \mathrm{kg} / \mathrm{m}^{3}$. Finally, the Transient Plane Source (TPS) method [32] was used to measure both thermal

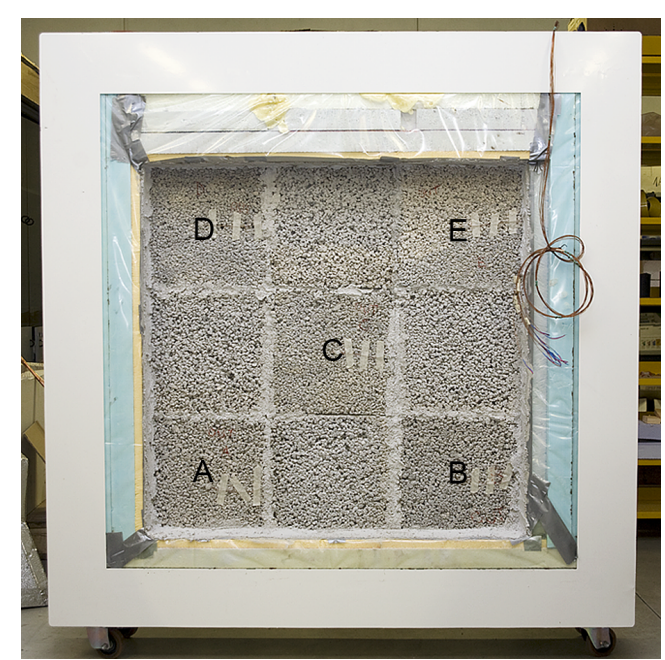

(a)

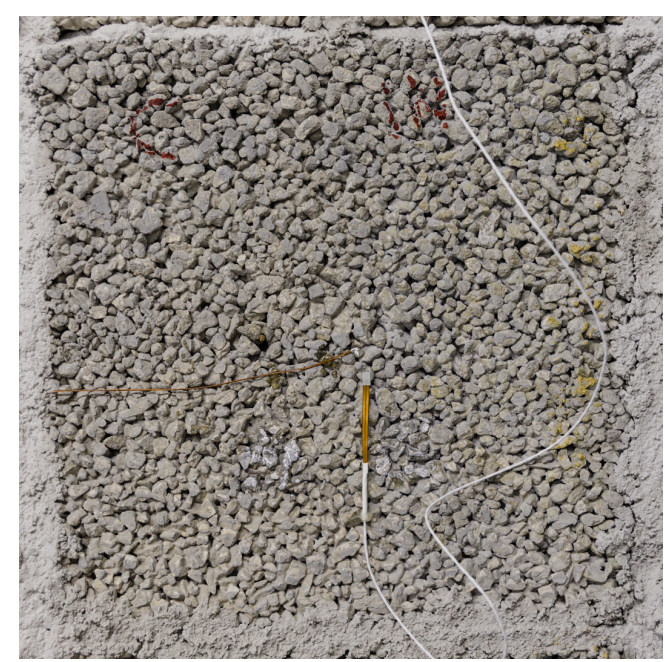

(b)

Figure 4: (a) Picture of the Breathing Wall sample, made of 9 no-fines concrete blocks, accommodated in the metal frame. Thermocouples are embedded in the five blocks labeled from A to E, while a heat flow meter is installed on one face of the central block $\mathrm{C}[12]$. (b) Detail of the surface of the $\mathrm{C}$ block facing Box 2, with the thermocouple and the heat flow meter glued on.

conductivity $\lambda_{s}$ and volumetric heat capacity $C_{s}$ of the solid matrix, that are equal to $(1.76 \pm 0.08) \mathrm{W} /(\mathrm{m} \cdot \mathrm{K})$ and $(2530 \pm 479) \mathrm{kJ} /\left(\mathrm{m}^{3} \cdot \mathrm{K}\right)$ respectively. At this point, since the Local Thermal Equilibrium assumption was introduced and the solid-fluid interaction at microscopic level is disregarded [27, 33], any thermo-physical quantity $\psi$ was calculated for the overall porous medium using the following equation: 


$$
\psi_{w}=\varepsilon \cdot \psi_{f}+(1-\varepsilon) \cdot \psi_{s}
$$

The results are summarized in Table 1, where the fluid properties refer to air.

Table 1: Thermo-physical and geometrical properties of the no-fines concrete mixture (wall) and its fluid and solid phases.

\begin{tabular}{lccc}
\hline quantity & solid & fluid & wall \\
\hline$\varepsilon[\%]$ & - & - & $30 \pm 2$ \\
$\lambda[\mathrm{W} /(\mathrm{m} \cdot \mathrm{K})]$ & $1.76 \pm 0.08$ & 0.025 & $1.24 \pm 0.06$ \\
$C\left[\mathrm{~kJ} /\left(\mathrm{m}^{3} \cdot \mathrm{K}\right)\right]$ & $2530 \pm 479$ & 1.236 & $1764 \pm 253$ \\
$\rho\left[\mathrm{kg} / \mathrm{m}^{3}\right]$ & $2483 \pm 87$ & 1.23 & $1739 \pm 61$ \\
\hline
\end{tabular}

The values calculated for the no-fines concrete Breathing Wall (last column in Table 1) were then used in the analytical model to calculate the temperature distribution across the sample and the heat flux density on one side.

\section{Methodology}

Six tests were performed: the first one is a null air velocity case, with the sample behaving as a traditional non-permeable wall; then, five incremental levels of airflow rate were applied, with air going from Box 1 to Box 2 with average air velocities equal to $0.001 \mathrm{~m} / \mathrm{s}$, $0.003 \mathrm{~m} / \mathrm{s}, 0.006 \mathrm{~m} / \mathrm{s}, 0.009 \mathrm{~m} / \mathrm{s}$ and $0.012 \mathrm{~m} / \mathrm{s}$, similarly to what was presented in [12].

As far as operative temperature boundary conditions are concerned, a sinusoidal variation was reproduced in Box 1, with an average value of $26^{\circ} \mathrm{C}$, a period of $24 \mathrm{~h}$ and a fluctuation amplitude of $6^{\circ} \mathrm{C}$, while in Box 2 the operative temperature is kept constant at $26{ }^{\circ} \mathrm{C}$. In this way a simplified summer condition for Milan (Italy) is simulated, with Box 1 representing the outdoor environment (without considering solar radiation) and Box 2 replicating a thermally controlled indoor environment. Temperature and airflow conditions assumed in the experimental campaign are summarized in Table 2 .

Table 2: Thermal and airflow conditions imposed in each test.

\begin{tabular}{lcc}
\hline Quantity & Box 1 & Box 2 \\
\hline$T(t)\left[{ }^{\circ} \mathrm{C}\right]$ & $26+6 \cdot \sin \left(\frac{2 \pi}{24 h} t\right)$ & 26 \\
$u_{f}[\mathrm{~m} / \mathrm{s}]$ & $0,0.001,0.003,0.006,0.009,0.012$ \\
& \multicolumn{2}{c}{ from Box 1 to Box 2 } \\
\hline
\end{tabular}

Each test required two steps: in the first one both chambers are kept at $26^{\circ} \mathrm{C}$ until the sample reaches the thermal equilibrium (i.e. all its sections show a temperature of $26^{\circ} \mathrm{C}$ throughout all their thickness). Then, the thermal fluctuation is started in Box 1; once the steady periodic condition is achieved, measurements are performed for a time equal to at least twice the fluctuation period (i.e. $48 \mathrm{~h}$ ).

The control strategy implemented to reproduce sinusoidal boundary condition is evaluated by comparing the operative temperature measured in each box at any given time $T(t)$ to the corresponding set-point value $T_{s p}(t)$. This also leads to the assessment of the thermal conditions reproducibility. For this reason, the control error is defined as $E(t)$ :

$$
E_{i}(t)=T_{s p, i}(t)-T_{i}(t)
$$

Due to its definition, negative values of $E(t)$ correspond to measured values greater than the set-point in a given moment, while measured temperatures below the desired value lead to positive results. The control error is calculated with reference to the operative temperature of both chambers. These data have then been used to calculate mean values, standard deviations and frequency distributions for each test.

Later, the experimental data collected are used to validate the analytical model for single layer Breathing Walls under steady periodic Dirichlet boundary conditions. During the six tests, cross-section temperature distribution was sampled every $5 \mathrm{~s}$ for all the five blocks provided with thermocouples inside the Breathing Wall sample investigated. However, since the effects of thermal stratification and inhomogeneities inside the DAVTB apparatus were already discussed in [12], in this paper only the data related to the center-most block $\mathrm{C}$ are investigated.

Going more in detail, the validation process is based on the data sets related to the last complete period of $24 \mathrm{~h}$ of the steady-periodic phase of each test: they are directly compared to the corresponding analytical curves calculated combining Eq. (4) and Eq. (16).

Although in each test operative temperatures are controlled, the analytical model in Eq. (1) is based on Dirichlet boundary conditions. Therefore, in order to generate the model solution, surface temperatures data collected during each test were firstly interpolated using the Curve Fitting Toolbox included in Matlab $($, and then used as boundary conditions. The interpolation process is based on the boundary conditions in Eq. (1) and provides, as results, the corresponding steady state component $\bar{T}$, fluctuation $\Delta T$, angular frequency $\omega$ and phase angle $\phi$. The thermo-physical properties of the sample reported in Table 1 are used to calculate the ana- 
lytical temperature distributions across the no-fines concrete wall and the heat flux density on the surface facing Box 2. These quantities were then compared to the corresponding measured ones, and the resulting deviations were further manipulated to obtain averages and standard deviations.

Finally, a sensitivity analysis is provided, performed to investigate the effects of the porous material volumetric heat capacity and of the heat flux meter features on the outcomes of the validation process.

\section{Results and discussion}

The outcomes of this work are twofold: first of all, it was assessed the ability of the DAVTB setup, along with the new control algorithm implemented, to replicate the desired steady-periodic thermal conditions at any airflow velocity imposed through the sample. Secondly, the analytical model previously presented was experimentally validated.

\subsection{Effectiveness of thermal control}

The control algorithm performance is analyzed through the evolution in time of the control errors for each test (Eq. 21). The corresponding frequency distributions are reported in Figure 5. Every graph shows that the control error fluctuation is generally contained in the range $\pm 0.4{ }^{\circ} \mathrm{C}$ and is centered around the $0{ }^{\circ} \mathrm{C}$. The control error average $\mu$ and standard deviation $\sigma$ are reported in Table 3 . Even though the general performance in replicating steady periodic condition is worse than what observed for steady state condition in [12], the average error is equal to $0.06{ }^{\circ} \mathrm{C}$ at most and the $\sigma$ is always below $0.15^{\circ} \mathrm{C}$. Both values are comparable to the accuracy of the calibrated thermocouples used in the DAVTB facility, as described in [12], thus confirming the effectiveness of the control strategy implemented to achieve sinusoidal variation of operative temperatures.

Table 3: Average and standard deviation of the control errors evaluated for each test performed according to Eq. 21, related to the expected instantaneous values for Box 1 and Box 2.

\begin{tabular}{cccccc}
\hline ID & $\begin{array}{c}\langle\mathbf{u}\rangle \\
{[\mathbf{m} / \mathbf{s}]}\end{array}$ & $\begin{array}{c}\mu_{\mathbf{1}} \\
{\left[{ }^{\circ} \mathbf{C}\right]}\end{array}$ & $\begin{array}{c}\sigma_{\mathbf{1}} \\
{\left[{ }^{\circ} \mathbf{C}\right]}\end{array}$ & $\begin{array}{c}\mu_{\mathbf{2}} \\
{\left[{ }^{\circ} \mathbf{C}\right]}\end{array}$ & $\begin{array}{c}\sigma_{\mathbf{2}} \\
{\left[{ }^{\circ} \mathbf{C}\right]}\end{array}$ \\
\hline 1 & 0 & 0.00 & 0.10 & -0.05 & 0.06 \\
2 & 0.001 & 0.01 & 0.08 & -0.06 & 0.05 \\
3 & 0.003 & 0.00 & 0.13 & -0.05 & 0.05 \\
4 & 0.006 & 0.04 & 0.09 & -0.03 & 0.08 \\
5 & 0.009 & 0.01 & 0.09 & 0.01 & 0.10 \\
6 & 0.012 & -0.02 & 0.12 & 0.03 & 0.08 \\
\hline
\end{tabular}

Even though the general reliability of the control strategy was assessed, in Figure 6 it is possible to observe some local discrepancies between the desired and the measured operative temperatures in both chambers, such as the one highlighted in the small graph zooming the time frame from hour 10 to 14 . These phenomena happen when there is a transition from heating to cooling regime or vice versa. As a matter of fact, when the control system switches from a working condition to the other it accordingly assumes a supply water temperature, while the actual temperature in the pipeline between the mixing valves and the supply terminals is still related to the previous working condition. For instance, if the system goes from heating to cooling, the circulation pump is turned on and the mixing valves are set to supply water at a temperature slightly below the operative temperature set point in the chamber. However, there will still be water inside the hydronic plant at a temperature above such set point, that will be forced to pass through the supply terminal inside the Box, leading to a sudden rise of the operative temperature while the system is supposed to cool it down. Although this phenomenon, related to the plant inertia, is hard to eliminate, its effects on the overall ability of the facility to reproduce steady periodic conditions are negligible, as Figure 5 clearly shows. Finally, in Figure 6 the effective alternation of heating and cooling regimes for both Box 1 and 2 is depicted: it shows that the real behaviour differs significantly from the ideal one represented in Figure 3 , since the control algorithm response is also affected by the laboratory room temperature and the sample thermal capacity.

The dynamic behaviour of the no-fines concrete sample can be inferred from Figure 7, in which the measured operative temperatures in (a) Box 1 and (b) Box 2 are shown, along with the surface temperatures measured during each test on both sides. It is possible to observe how the dynamic behaviour of the sample is affected by the crossing airflow velocity: first, the time delay between the peak of the operative temperature in Box 1 and the temperature measured at the surface facing Box $2(x=L)$ decreases from $4.3 \mathrm{~h}\left(u_{f}=0 \mathrm{~m} / \mathrm{s}\right)$ to less then $3 \mathrm{~h}\left(u_{f}=0.012 \mathrm{~m} / \mathrm{s}\right)$. Moreover, the maximum fluctuation amplitude of the surface temperature is affected, going from $20 \%$ (null velocity) to almost $60 \%$ (maximum velocity) of the Box 1 operative temperature fluctuation amplitude. Both these phenomena show how the introduction of the advective heat flux through the sample enhances the thermal coupling between the sides of the wall sample, namely decreases the wall effective capacity. 


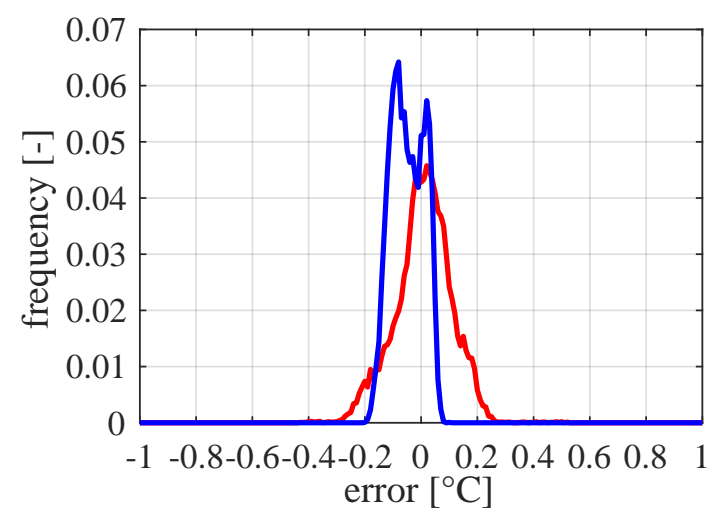

(a) $I D 1-0 \mathrm{~m}^{3} /\left(\mathrm{m}^{2} \cdot \mathrm{s}\right)$

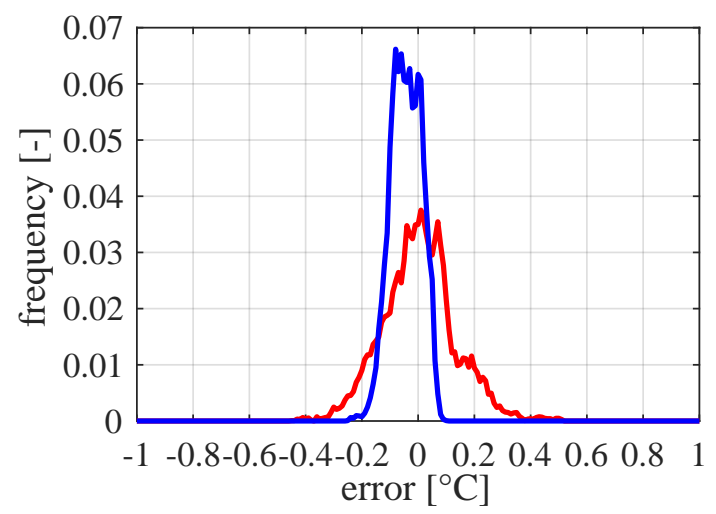

(c) $I D 3-0.003 \mathrm{~m}^{3} /\left(\mathrm{m}^{2} \cdot \mathrm{s}\right)$

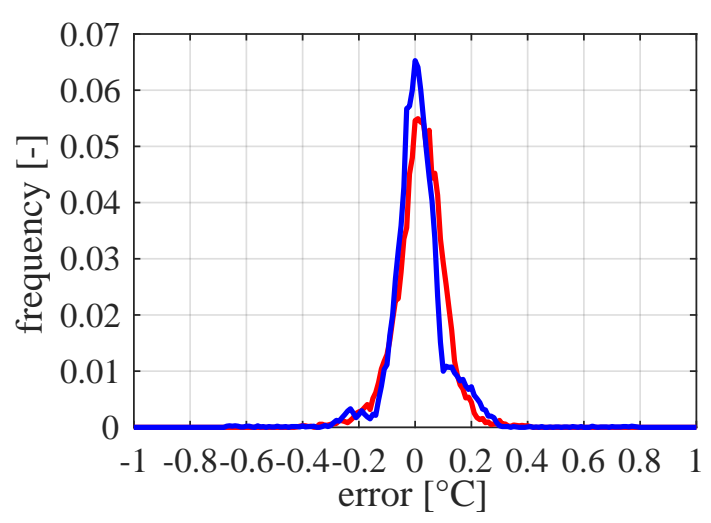

(e) $I D 5-0.009 \mathrm{~m}^{3} /\left(\mathrm{m}^{2} \cdot \mathrm{s}\right)$

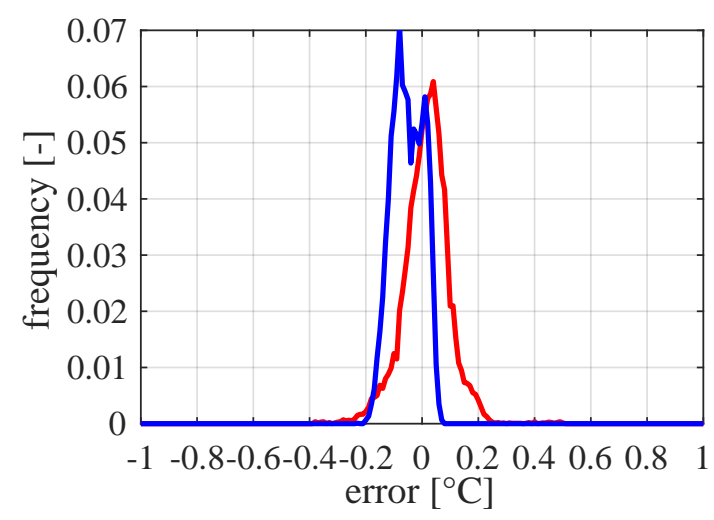

(b) $I D 2-0.001 \mathrm{~m}^{3} /\left(\mathrm{m}^{2} \cdot \mathrm{s}\right)$

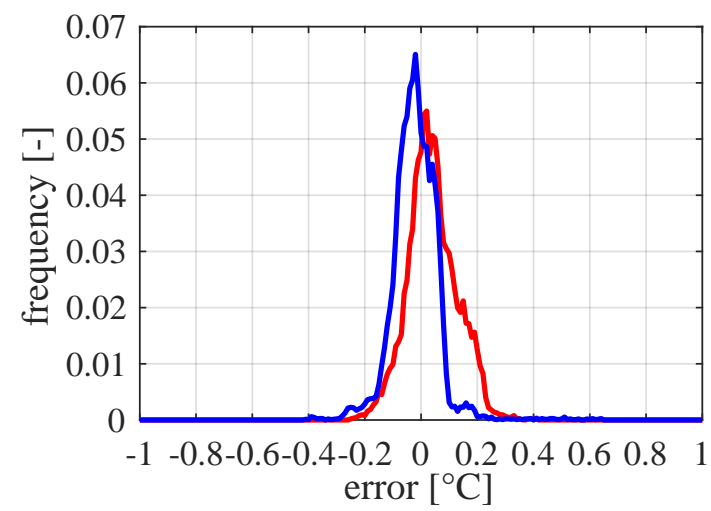

(d) $I D 4-0.006 \mathrm{~m}^{3} /\left(\mathrm{m}^{2} \cdot \mathrm{s}\right)$

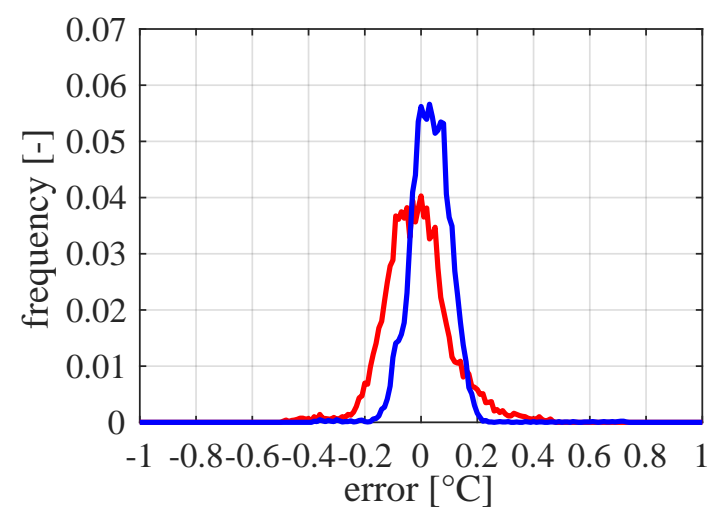

(f) $I D 6-0.012 \mathrm{~m}^{3} /\left(\mathrm{m}^{2} \cdot \mathrm{s}\right)$

\footnotetext{
Box 1 (steady periodic)
Box 2 (steady state)
}

Figure 5: Frequency distribution of control errors related to operative temperature in Box 1 and 2, and their difference $\left(T_{2}-T_{1}\right)$, for each airflow rate experimentally reproduced: (a) $0 \mathrm{~m}^{3} /\left(\mathrm{m}^{2} \cdot \mathrm{s}\right)$ (airtight), (b) $\left.0.001 \mathrm{~m}^{3} /\left(\mathrm{m}^{2} \cdot \mathrm{s}\right),(\mathrm{c})\right] 0.003 \mathrm{~m}^{3} /\left(\mathrm{m}^{2} \cdot \mathrm{s}\right)$, (d) $0.006 \mathrm{~m}^{3} /\left(\mathrm{m}^{2} \cdot \mathrm{s}\right),(\mathrm{e}) 0.009 \mathrm{~m}^{3} /\left(\mathrm{m}^{2} \cdot \mathrm{s}\right)$ and $(\mathrm{f}) 0.012 \mathrm{~m}^{3} /\left(\mathrm{m}^{2} \cdot \mathrm{s}\right)$.

\subsection{Comparison between analytical and measured} temperature profiles

In Table 4 the parameters of the interpolation of the 
time $[\mathrm{h}]$

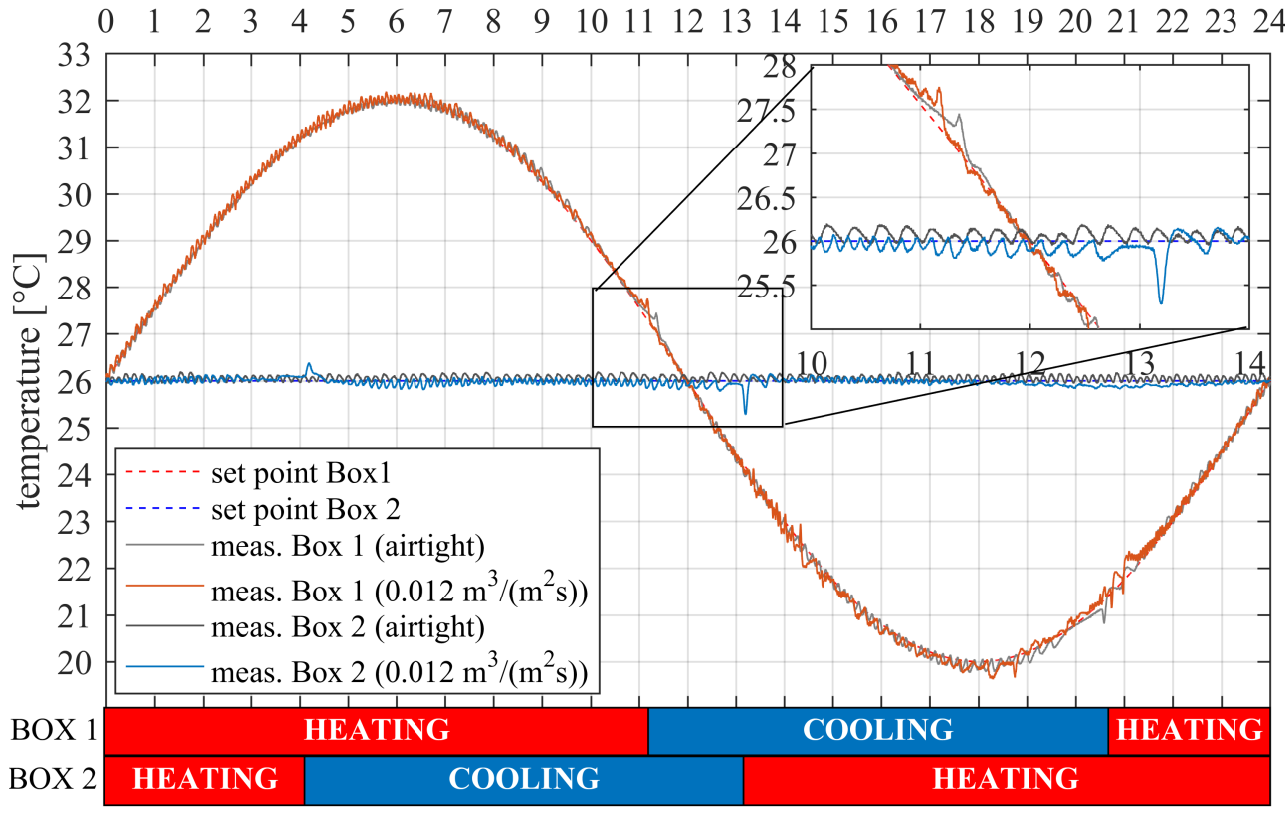

Figure 6: Operative temperatures in Box 1 and Box 2 measured in two tests (airtight and $0.012 \mathrm{~m}^{3} /\left(\mathrm{m}^{2} \mathrm{~s}\right)$ ) are compared with the respective instantaneous set-point values. The deviations related to the switch in working conditions (heating to cooling or vice versa) are highlighted. Heating and cooling regimes are shown for Box 1 (B1) and Box 2 (B2).

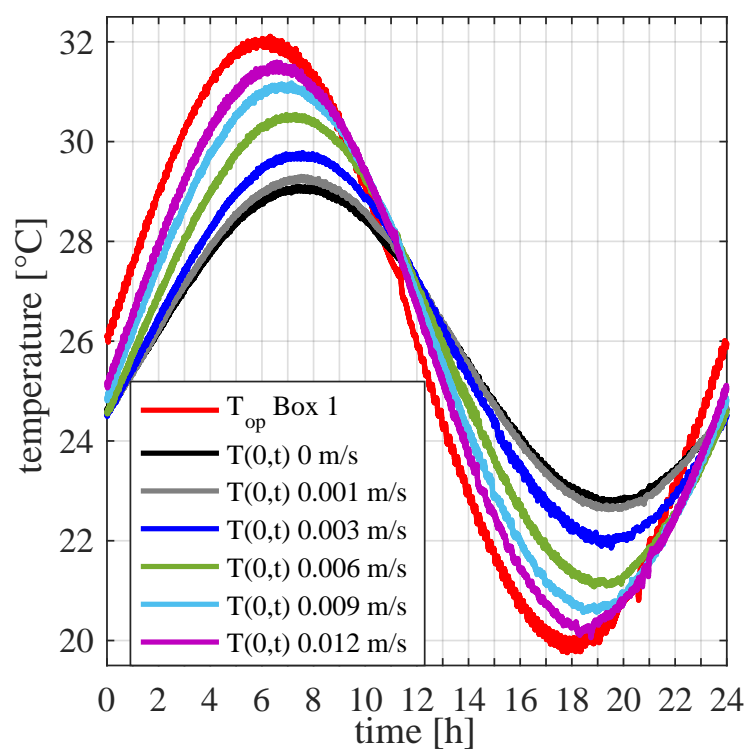

(a)

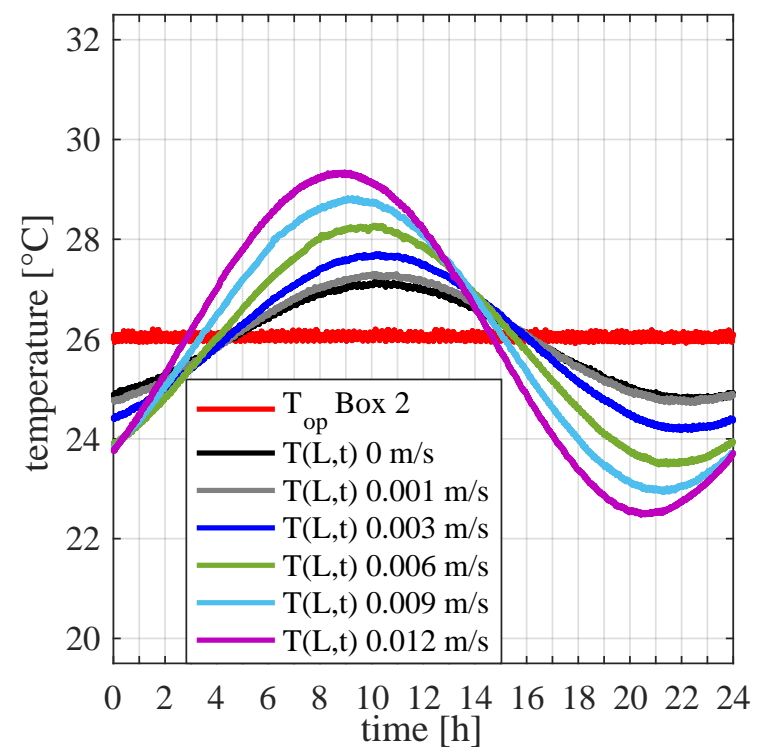

(b)

Figure 7: Measured operative temperature and surface temperature for each test on the (a) Box 1 side and the (b) Box 2 side.

boundary conditions in Eq. (1) are reported.

Starting from the boundary conditions obtained applying the values reported in Table 4 to Eq. (2) at $x=$ $0 \mathrm{~m}$ (surface facing Box 1) and $x=0.15 \mathrm{~m}$ (surface facing Box 2) for every test performed, the steady state and the steady periodic parts of the temperature distribution across the sample were calculated, using Eq. (4) and Eq. (16). 


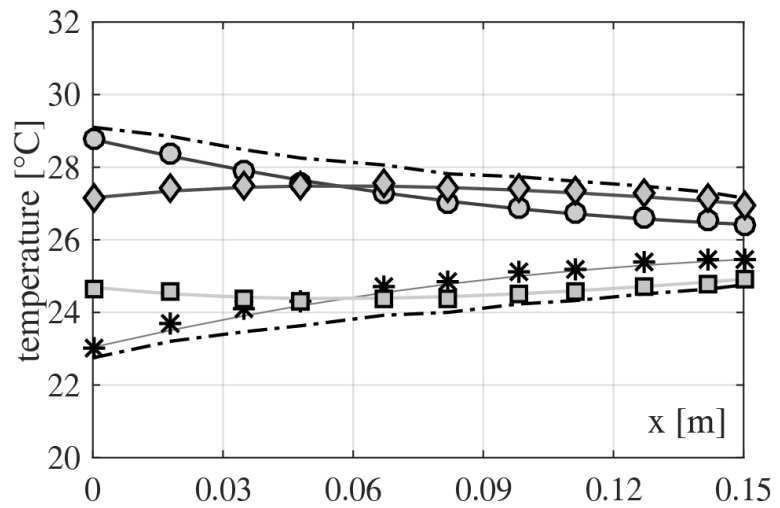

(a) $I D 1-0 \mathrm{~m} / \mathrm{s}$
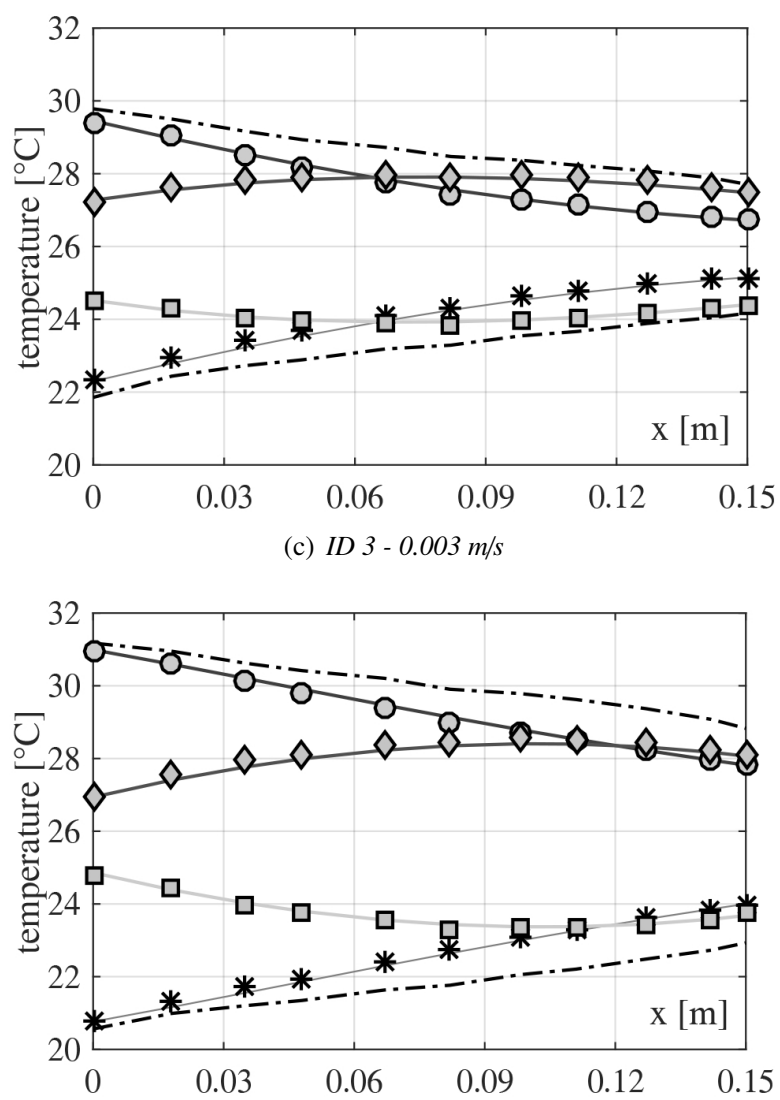

(e) $I D 5-0.009 \mathrm{~m} / \mathrm{s}$

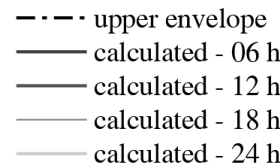

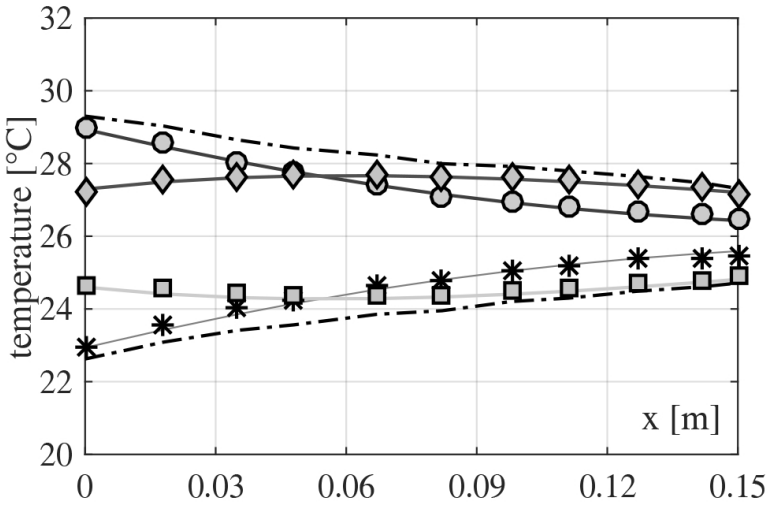

(b) $I D 2-0.001 \mathrm{~m} / \mathrm{s}$
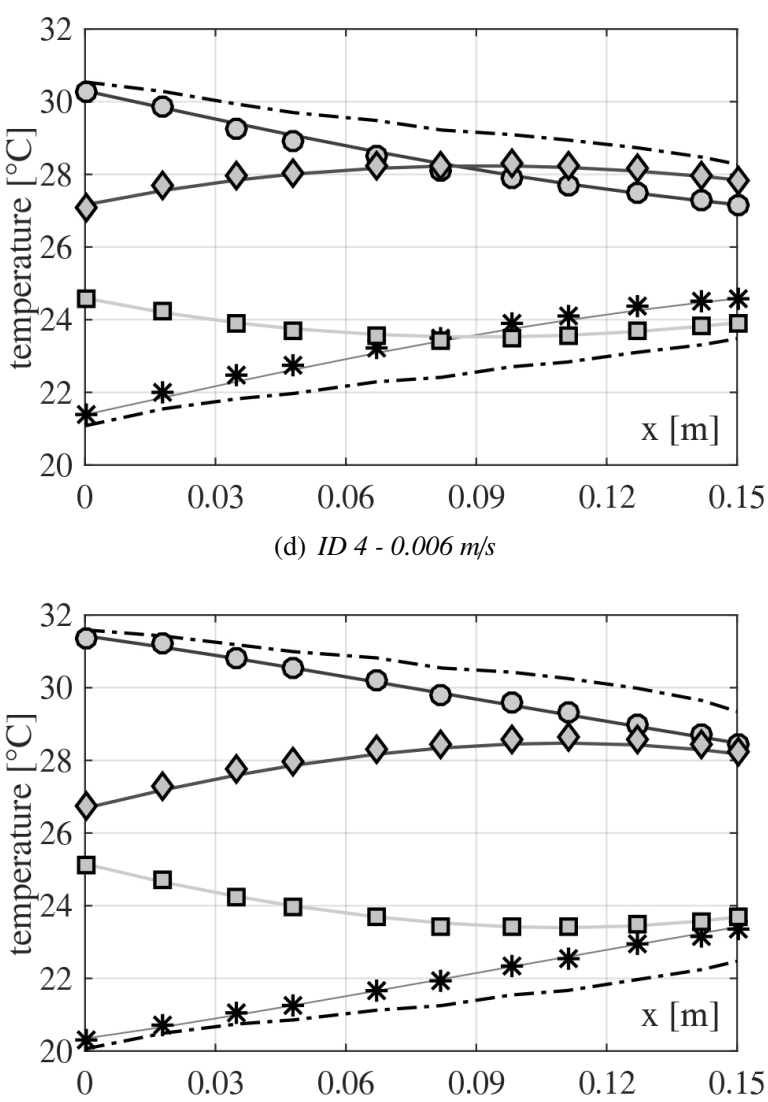

(f) $I D 6-0.012 \mathrm{~m} / \mathrm{s}$

$$
\begin{array}{cc}
-\cdot-\cdot & \text { lower envelope } \\
\circ & \text { measured }-06 \mathrm{~h} \\
\diamond & \text { measured }-12 \mathrm{~h} \\
* & \text { measured }-18 \mathrm{~h} \\
\square & \text { measured }-24 \mathrm{~h}
\end{array}
$$

Figure 8: Measured and calculated temperature profiles across the central block of the sample wall at four different moments $(6 \mathrm{~h}, 12 \mathrm{~h}, 18 \mathrm{~h}$ and $24 \mathrm{~h})$, for the various air velocities: (a) $0 \mathrm{~m} / \mathrm{s},(\mathrm{b}) 0.001 \mathrm{~m} / \mathrm{s}$, (c) $0.003 \mathrm{~m} / \mathrm{s}$, (d) $0.006 \mathrm{~m} / \mathrm{s},(\mathrm{e}) 0.009 \mathrm{~m} / \mathrm{s}$ and (f) $0.012 \mathrm{~m} / \mathrm{s}$. 
Table 4: Coefficients obtained through the interpolation of measured surface temperatures for each test.

\begin{tabular}{ccccccccc}
\hline & \multicolumn{3}{c}{ Box 1 } & \multicolumn{4}{c}{ Box 2 } \\
ID & $\begin{array}{c}\overline{\mathbf{T}} \\
{\left[\mathbf{C}^{\circ}\right]}\end{array}$ & $\begin{array}{c}\Delta \mathbf{T} \\
{\left[\mathbf{C}^{\circ}\right]}\end{array}$ & $\begin{array}{c}\omega \\
{[\mathbf{r d} / \mathbf{s}]}\end{array}$ & $\begin{array}{c}\phi \\
{[\mathbf{r d}]}\end{array}$ & $\begin{array}{c}\overline{\mathbf{T}} \\
{\left[\mathbf{C}^{\circ}\right]}\end{array}$ & $\begin{array}{c}\Delta \mathbf{T} \\
{\left[\mathbf{C}^{\circ}\right]}\end{array}$ & $\begin{array}{c}\omega \\
{[\mathbf{r d} / \mathbf{s}]}\end{array}$ & $\begin{array}{c}\phi \\
{[\mathbf{r d}]}\end{array}$ \\
\hline 1 & 25.91 & 3.12 & $7.30 \cdot 10^{-5}$ & -1.993 & 25.95 & 1.15 & $7.30 \cdot 10^{-5}$ & -2.720 \\
2 & 25.94 & 3.29 & $7.28 \cdot 10^{-5}$ & -2.000 & 26.01 & 1.27 & $7.27 \cdot 10^{-5}$ & -2.802 \\
3 & 25.88 & 3.84 & $7.29 \cdot 10^{-5}$ & -1.950 & 25.94 & 1.73 & $7.28 \cdot 10^{-5}$ & -2.674 \\
4 & 25.85 & 4.65 & $7.30 \cdot 10^{-5}$ & -1.869 & 25.88 & 2.36 & $7.28 \cdot 10^{-5}$ & -2.565 \\
5 & 25.88 & 5.22 & $7.29 \cdot 10^{-5}$ & -1.782 & 25.89 & 2.90 & $7.23 \cdot 10^{-5}$ & -2.403 \\
6 & 25.89 & 5.60 & $7.29 \cdot 10^{-5}$ & -1.723 & 25.94 & 3.38 & $7.26 \cdot 10^{-5}$ & -2.290 \\
\hline
\end{tabular}

The analytical profiles obtained with the average values of the no-fines concrete thermo-physical properties (Table 1) are reported in Figure 8 and compared with the corresponding experimental data. Each graph deals with a different test and reports the measured (dots) and the calculated (lines) temperature distribution across the sample at four different moments of the $24 \mathrm{~h}$ period, along with the envelopes of these fluctuations (i.e. either the maximum or the minimum temperature achieved at every location of the wall cross section during each test).

As far as deviation between measured and calculated data is concerned, average values go from $0.06{ }^{\circ} \mathrm{C}$ to $0.08{ }^{\circ} \mathrm{C}$, while standard deviations are equal to $0.04{ }^{\circ} \mathrm{C}$ $0.05^{\circ} \mathrm{C}$. This means that the modeling errors are within the probe accuracy of $0.15{ }^{\circ} \mathrm{C}$ estimated for the thermocouples after their calibration, as reported in [12]. These findings allow to consider the analytical model as validated, for what concerns its ability to faithfully reproduce the temperature distribution in a single-layer Breathing Wall under Dirichlet steady periodic conditions.

At this point, a sensitivity analysis was performed in order to evaluate the effects of the uncertainties related to the porous material thermo-physical quantities on the results of the calculations. For this reason, temperature distributions were recalculated considering the minimum and the maximum values for density and specific heat of the no-fines concrete, either minimizing or maximizing the heat capacity of the material. Thermal conductivity was not included in this analysis, since it was already thoroughly investigated in [12]. Then, the agreement between calculated and measured data has been re-evaluated, leading to new averages and standard deviations. All results are reported in Table 5 .

As shown in Table 5, a deviation of the thermophysical properties of the material toward a lower heat capacity leads to worsening the standard deviation $\sigma$ of the difference between experimental data and calculated temperatures for every airflow velocity investi-
Table 5: Average and standard deviation of the differences between measured and calculated temperatures for each of the six tests performed, considering three levels of heat capacity of the no-fines concrete, according to the values and ranges reported in the wall column in Table 1

\begin{tabular}{ccccccc}
\hline$u_{f}[\mathbf{m} / \mathbf{s}]$ & $\mathbf{0}$ & $\mathbf{0 . 0 0 1}$ & $\mathbf{0 . 0 0 3}$ & $\mathbf{0 . 0 0 6}$ & $\mathbf{0 . 0 0 9}$ & $\mathbf{0 . 0 1 2}$ \\
\hline \multicolumn{6}{c}{ lower heat capacity -1511} & $\mathrm{~kJ} /\left(\mathrm{m}^{3} \mathrm{~K}\right)$ \\
\hline$\mu\left[{ }^{\circ} \mathrm{C}\right]$ & -0.04 & -0.02 & -0.03 & -0.02 & -0.04 & -0.05 \\
$\sigma\left[{ }^{\circ} \mathrm{C}\right]$ & 0.10 & 0.09 & 0.12 & 0.16 & 0.15 & 0.12 \\
\hline \multicolumn{6}{c}{ average heat capacity $-1764 \mathrm{~kJ} /\left(\mathrm{m}^{3} \mathrm{~K}\right)$} \\
\hline$\mu\left[{ }^{\circ} \mathrm{C}\right]$ & -0.04 & -0.02 & -0.03 & -0.02 & -0.04 & -0.05 \\
$\sigma\left[{ }^{\circ} \mathrm{C}\right]$ & 0.06 & 0.07 & 0.07 & 0.09 & 0.08 & 0.06 \\
\hline \multicolumn{7}{c}{ upper heat capacity $-2017 \mathrm{~kJ} /\left(\mathrm{m}^{3} \mathrm{~K}\right)$} \\
\hline$\mu\left[{ }^{\circ} \mathrm{C}\right]$ & -0.04 & -0.03 & -0.04 & -0.02 & -0.04 & -0.06 \\
$\sigma\left[{ }^{\circ} \mathrm{C}\right]$ & 0.05 & 0.08 & 0.04 & 0.05 & 0.06 & 0.11 \\
\hline
\end{tabular}

gated. A greater heat capacity shows improvements for some airflow velocities $(0 \mathrm{~m} / \mathrm{s}, 0.003 \mathrm{~m} / \mathrm{s}, 0.006 \mathrm{~m} / \mathrm{s}$ and $0.009 \mathrm{~m} / \mathrm{s}$ ) both in terms of average and standard deviation, while in the other cases $(0.001 \mathrm{~m} / \mathrm{s}$ and $0.012 \mathrm{~m} / \mathrm{s})$ worse results are obtained, leading to a generally better representation of the experimental results by the analytical model. This means that the real values of the nofines concrete density and specific heat capacity might be greater then the average values reported in Table 1 , corresponding to a greater heat capacity of the porous material, since if such averages were correct, symmetrical deviations would be found.

\subsection{Comparison between analytical and measured conduction heat flux densities}

The second step of the validation process concerned the evaluation of the conduction heat flux densities using Eq. 6 and Eq. 18 for every airflow rate condition investigated and the comparison with the measured ones. Since the latter are affected by high frequency fluctuations (see Figure 9), they were smoothed through an interpolation process. 


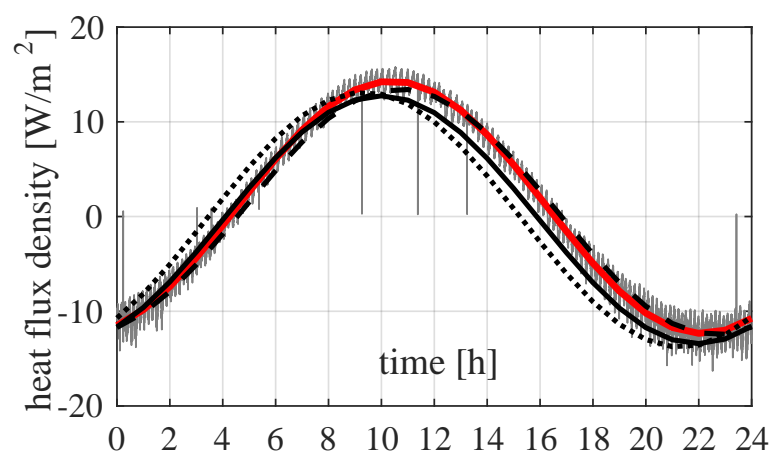

(a) $I D 1-0 \mathrm{~m} / \mathrm{s}$

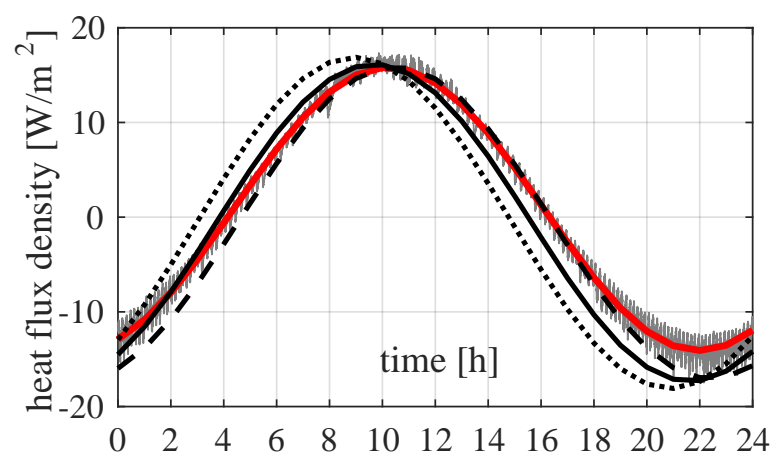

(c) ID $3-0.003 \mathrm{~m} / \mathrm{s}$

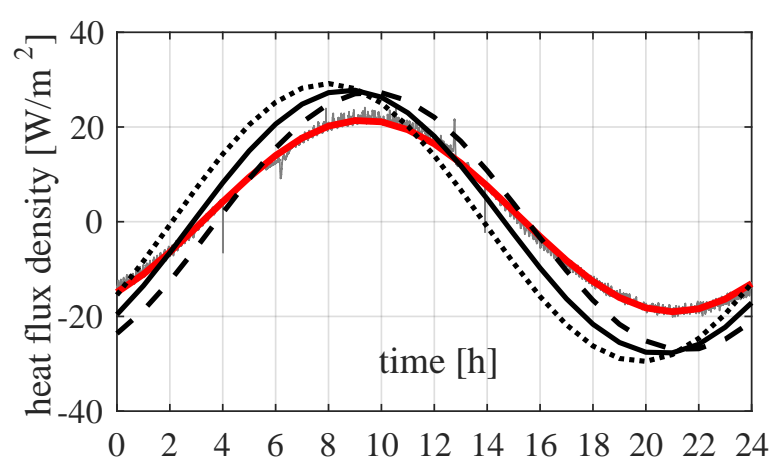

(e) $I D 5-0.009 \mathrm{~m} / \mathrm{s}$

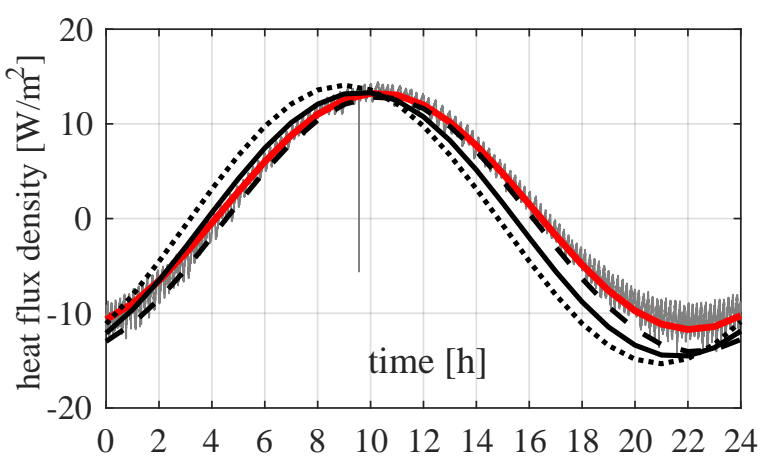

(b) $I D 2-0.001 \mathrm{~m} / \mathrm{s}$

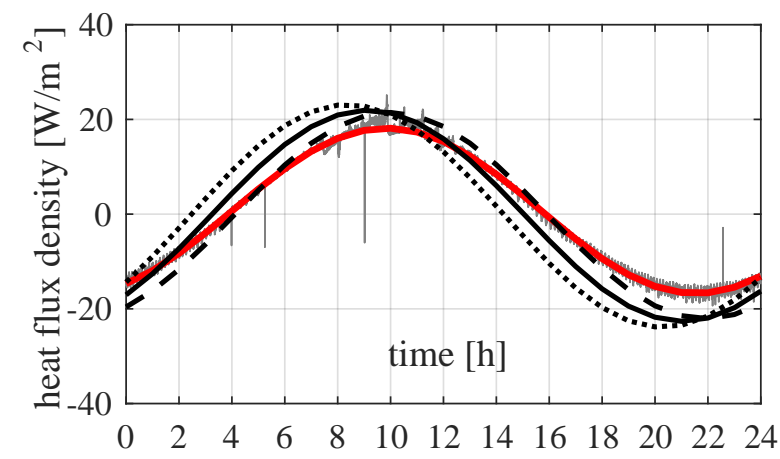

(d) $I D 4-0.006 \mathrm{~m} / \mathrm{s}$

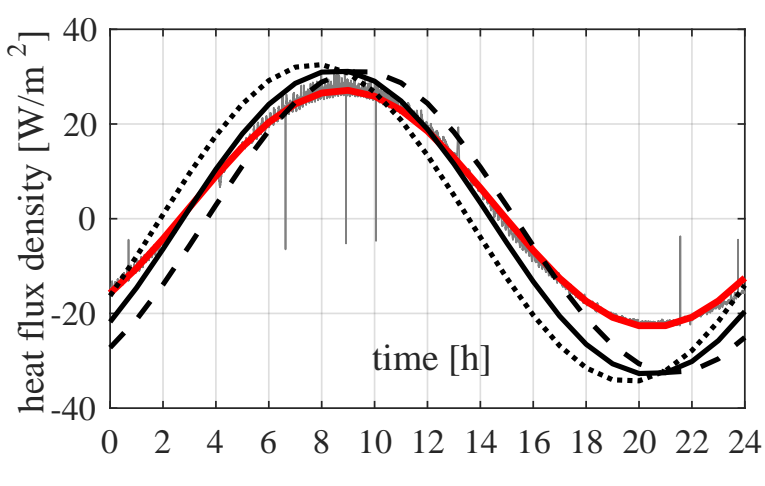

(f) $I D 6-0.012 \mathrm{~m} / \mathrm{s}$

$$
\begin{aligned}
& \text { measured } \\
& \text { interpolated } \\
& \text { average heat capacity } \\
& \ldots . . . . \text { lower heat capacity }
\end{aligned}
$$

Figure 9: Measured and calculated time fluctuations of conduction heat flux densities on the center of the sample surface facing Box 2, for the various air velocities investigated: (a) $0 \mathrm{~m} / \mathrm{s}$, (b) $0.001 \mathrm{~m} / \mathrm{s}$, (c) $0.003 \mathrm{~m} / \mathrm{s}$, (d) $0.006 \mathrm{~m} / \mathrm{s}$, (e) $0.009 \mathrm{~m} / \mathrm{s}$ and (f) $0.012 \mathrm{~m} / \mathrm{s}$. Calculations refer to three levels of heat capacity of the porous material. 
Like what has been done with the temperatures, calculations were performed considering three different levels of heat capacity for the no-fines concrete, based on the values reported in Table 1 The experimental and analytical results obtained for each test are shown in Figure 9 .

First of all, it is possible to observe that the measured values (light gray curves) feature high-frequency oscillations in every test, with some sudden spikes and drops. These fluctuations, caused by the air motion over the heat flow meter free surface, are filtered through the interpolation process, that leads to the smooth red curves used as a reference.

Moreover, Figure 9 also shows how the calculated heat flux densities fail to adequately represent the interpolation of the measured quantities, both in terms of oscillation amplitude and time delay, even considering the flow meter accuracy. However, even though the fluctuation amplitude is still not reproduced correctly, better results are obtained in terms of time dependency when the higher heat capacity is considered: the location in time of maximum and minimum heat flux density values is better caught, possibly with a slightly exaggerated delay. Average and standard deviations of the differences between calculated and interpolated values for each test and every heat capacity levels are summarized in Table 6

Table 6: Average and standard deviation of the differences between measured and calculated conduction heat flux densities for each test, considering three levels of heat capacity of the no-fines concrete, according to the values and ranges reported in the wall column in Table 1

\begin{tabular}{ccccccc}
\hline$u_{f}[\mathbf{m} / \mathbf{s}]$ & $\mathbf{0}$ & $\mathbf{0 . 0 0 1}$ & $\mathbf{0 . 0 0 3}$ & $\mathbf{0 . 0 0 6}$ & $\mathbf{0 . 0 0 9}$ & $\mathbf{0 . 0 1 2}$ \\
\hline \multicolumn{6}{c}{ lower heat capacity $-1511 \mathrm{~kJ} /\left(\mathrm{m}^{3} \mathrm{~K}\right)$} \\
\hline$\mu\left[\mathrm{W} / \mathrm{m}^{2}\right]$ & 1.02 & 1.26 & 1.21 & 0.76 & 1.23 & 2.72 \\
$\sigma\left[\mathrm{W} / \mathrm{m}^{2}\right]$ & 2.65 & 3.59 & 4.25 & 6.97 & 8.81 & 8.31 \\
\hline \multicolumn{6}{c}{ average heat capacity -1764} & $\mathrm{~kJ} /\left(\mathrm{m}^{3} \mathrm{~K}\right)$ \\
\hline$\mu\left[\mathrm{W} / \mathrm{m}^{2}\right]$ & 1.06 & 1.30 & 1.28 & 0.88 & 1.39 & 2.96 \\
$\sigma\left[\mathrm{W} / \mathrm{m}^{2}\right]$ & 1.08 & 1.91 & 2.05 & 4.27 & 5.93 & 5.25 \\
\hline \multicolumn{7}{c}{ upper heat capacity $-2017 \mathrm{~kJ} /\left(\mathrm{m}^{3} \mathrm{~K}\right)$} \\
\hline$\mu\left[\mathrm{W} / \mathrm{m}^{2}\right]$ & 0.28 & 1.34 & 1.34 & 0.99 & 1.55 & 3.18 \\
$\sigma\left[\mathrm{W} / \mathrm{m}^{2}\right]$ & 0.77 & 0.74 & 1.38 & 3.24 & 5.46 & 6.55 \\
\hline
\end{tabular}

This analysis confirms the outcomes of the temperatures investigation: the analytical model is able to assess the overall trend of the heat flux density at one surface when a value higher than average is considered for the material heat capacity, meaning that the real density and specific heat capacity of the porous material considered in this work lay in the upper half of the range indicated in Table 1. However, variations in heat capacity alone are not enough to explain the discrepancies between calculated values and the interpolation of measured data for the conductive heat flux, since the difference in fluctuation amplitude remains high.

It is then possible to identify two more sources for the discrepancies between measured and analytically calculated heat flux density. On one side, its calculation can be affected by errors in the definition of boundary conditions, due to uncertainties in temperature measurements. On the other side, measurement errors might be introduced by features of the heat flow meter itself: its emissivity not matching the no-fines concrete one, the effects of its thermal resistance (approximately $7.74 \cdot 10^{-4} \mathrm{~m}^{2} \mathrm{~K} / \mathrm{W}$ ) might not be negligible and, finally, the thermal contact between the probe and the sample surface could be not ideal.

The effects of the boundary conditions uncertainties on the calculated conductive heat flux density were evaluated, taking into account the thermocouple accuracy of $0.15{ }^{\circ} \mathrm{C}$. Namely, it was summed or subtracted to both stationary components of the surface temperatures. In this way, the stationary temperature difference was either decreased or increased by $0.30{ }^{\circ} \mathrm{C}$. The resulting calculated heat flux densities are displayed in Figure 10 for $0 \mathrm{~m} / \mathrm{s}$ and $0.012 \mathrm{~m} / \mathrm{s}$ only. Both cases show how a small uncertainty in the definition of temperature boundary conditions has a strong effect on the time distribution of the calculated heat flux density: whenever its stationary component is manipulated according to the thermocouples accuracy, an instantaneous range of heat flux density fluctuations is achieved, which in most cases includes the fitting of the measured values.

Then, the effects of the features of the heat flow meter were investigated. However, since it is difficult to isolate the effects of these features when boundary conditions change over time and the material heat capacity is involved, few additional steady state tests were performed imposing a $25{ }^{\circ} \mathrm{C}$ operative temperature difference between the two chambers $\left(20{ }^{\circ} \mathrm{C}\right.$ in Box 1 and $45^{\circ} \mathrm{C}$ in Box 2) and three different specific airflow rates $\left(0 \mathrm{~m}^{3} /\left(\mathrm{m}^{2} \mathrm{~s}\right), 0.003 \mathrm{~m}^{3} /\left(\mathrm{m}^{2} \mathrm{~s}\right)\right.$ and $\left.0.012 \mathrm{~m}^{3} /\left(\mathrm{m}^{2} \mathrm{~s}\right)\right)$. Collected data were then used to quantify each of the other two effects previously discussed. Then, after a direct comparison to their expected values, calculated considering the heat transfer through the sample, it was found that the heat flux density is underestimated by the sensor itself. Measured heat flux in the three cases is equal to $89.8 \mathrm{~W} / \mathrm{m}^{2}, 100.0 \mathrm{~W} / \mathrm{m}^{2}$ and $113.0 \mathrm{~W} / \mathrm{m}^{2}$, while the calculated one (with no correction considered) is equal to $93.3 \mathrm{~W} / \mathrm{m}^{2}, 110.9 \mathrm{~W} / \mathrm{m}^{2}$ and $148.7 \mathrm{~W} / \mathrm{m}^{2}$.

As far as the surface radiative property is concerned, it has been established through spectrophotometry mea- 


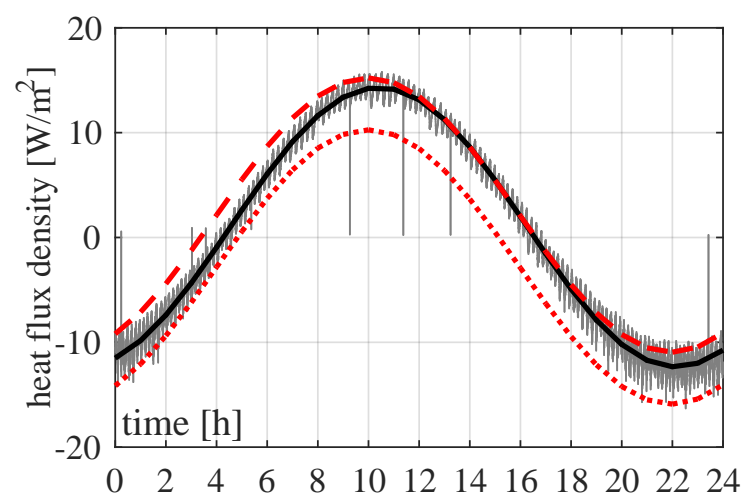

(a) $I D 1-0 \mathrm{~m} / \mathrm{s}$

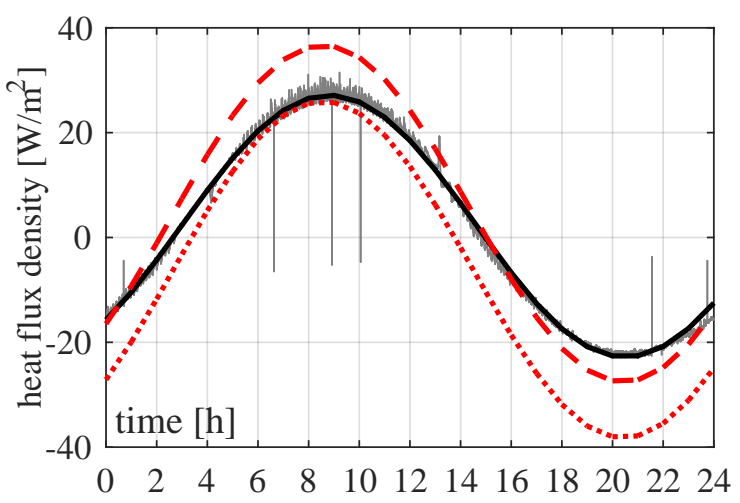

(b) $I D 6-0.012 \mathrm{~m} / \mathrm{s}$

$$
\begin{aligned}
& \text { measured }-\quad \Delta \mathrm{T}_{\mathrm{st}}-0.30^{\circ} \mathrm{C} \\
& \text { fitting } \quad \ldots \ldots . . . \Delta \mathrm{T}_{\mathrm{st}}+0.30^{\circ} \mathrm{C}
\end{aligned}
$$

Figure 10: Effect of error in surface temperature measurements, due to thermocouples accuracy, on conductive heat flux calculation at (a) $0 \mathrm{~m} / \mathrm{s}$ and (b) $0.012 \mathrm{~m} / \mathrm{s}$.

surements that the heat flow meter emissivity is equal to 0.8 , while for the sample it is 0.9 . By adjusting the measured heat flux in order to take this difference into account, the discrepancy between measures and calculated values drops from $3.9 \%$ to $0.76 \%$ with $\mathrm{u}_{f}=0 \mathrm{~m} / \mathrm{s}$, from $10.9 \%$ to $4.42 \%$ with $\mathrm{u}_{f}=0.003 \mathrm{~m} / \mathrm{s}$ and from $31.6 \%$ to $20.94 \%$ with $\mathrm{u}_{f}=0.012 \mathrm{~m} / \mathrm{s}$. This means that the error introduced by the difference in emissivity between the heat flow meter and the sample has to be taken into consideration.

Dealing now with the sensor thermal resistance only, adjusting the measurements to take it into account leads to less relevant improvements in the discrepancy between model and measures (becoming $2.82 \%, 10.05 \%$ and $30.92 \%$ ). Finally, the effect of a potential contact resistance between the sensor and the concrete wall surface was qualitatively studied, observing that even a thin air layer (around $0.1 \mathrm{~mm}$ ) between the sensor and the sample can introduce a significant error. However, since it is impossible to effectively quantify this additional thermal resistance, no further detail will be provided.

In conclusion, the outcomes of this analysis can be extended to the steady periodic tests performed: the tendency of the sensor to underestimate the heat flux explains the discrepancies between the measured and the calculated quantities displayed in Figure 9. This underestimation is caused by the difference in emissivity between the sample and the heat flow meter, along with the presence of parasitical thermal resistances. This also shows that the heat flow density measurement on a rough surface subject to both radiative and convective heat transfer is intrinsically prone to error due to the complexity of the phenomena involved. In the end, since it was also demonstrated that a good agreement between the trend of measured and calculated data can be achieved after a careful evaluation of the sample heat capacity, it is safe to consider the ability of the analytical model to portray conduction heat flux density fluctuations as validated.

\section{Conclusions}

In this work, an analytical model to evaluate the temperature distribution across Breathing Wall component under steady-periodic Dirichlet conditions is derived, representing a variation of the analytical model in [26] more suitable to experimental validation, which is in fact provided in this paper.

The experimental validation was performed using the DAVTB apparatus presented in previous works by the Authors [12, 13]. A new function was added to the control algorithm, in order to introduce the steady periodic temperature reproduction: the set-point changes sinusoidally in time and the algorithm switches from heating to cooling regime and vice versa whenever needed. The effectiveness of this new function has been tested, comparing the desired value for the set-point operative temperature to the corresponding measured one at several airflow velocities. The average control error is always below $0.06{ }^{\circ} \mathrm{C}$, with a standard deviation below $0.13{ }^{\circ} \mathrm{C}$, showing the algorithm effectiveness in tracking a fluctuating set-point. 
First of all the experimental measurements show how the Breathing Wall sample dynamic behaviour is affected by the airflow velocity: the time delay between the boundary condition peak on one side and the surface temperature peak on the other side decreases with increasing airflow velocity. At the same time, the surface temperature fluctuation amplitude grows with airflow velocity. This means that the air moving from one environment to the other increases the thermal coupling between them, namely the effective thermal capacity of the wall is decreased with respect to the airtight condition.

The next step was the validation of the analytical model discussed. The temperature distributions measured in different tests, with airflow velocities from $0 \mathrm{~m} / \mathrm{s}$ to $0.012 \mathrm{~m} / \mathrm{s}$, were compared to the model outputs. A reference group of calculations is based on the average heat capacity of the sample material, and shows a good agreement with the corresponding calculated values, with an average error of $0.06{ }^{\circ} \mathrm{C}-0.08{ }^{\circ} \mathrm{C}$ and a standard deviation under $0.05{ }^{\circ} \mathrm{C}$, within the measurement accuracy of thermocouples. Conversely, heat flux density reveals a greater discrepancy between measured and calculated quantities, with an average error from $7.47 \%\left(1.06 \mathrm{~W} / \mathrm{m}^{2}\right)$ to $10.90 \%\left(2.96 \mathrm{~W} / \mathrm{m}^{2}\right)$ and standard deviation from $7.60 \%\left(1.08 \mathrm{~W} / \mathrm{m}^{2}\right)$ to $19.39 \%$ $\left(5.93 \mathrm{~W} / \mathrm{m}^{2}\right)$. The measured quantity is not faithfully replicated either in amplitude or in time shift. Furthermore, since the maximum measured heat flux goes from around $15 \mathrm{~W} / \mathrm{m}^{2}$ to $30 \mathrm{~W} / \mathrm{m}^{2}$, the error cannot be explained only by the probe accuracy.

This first group of observations led to the need for a sensitivity analysis. It was found that:

1. considering a material heat capacity greater than the average leads to a generally better performance of the model in predicting both temperature distribution and heat flux density at the $x=L$ surface;

2. the calculated heat flux density can be significantly affected by the variation of the measured surface temperatures due to the thermocouple accuracy of $\pm 0.15^{\circ} \mathrm{C}$;

3. taking into account the difference between heat flow meter and sample emissivity can mitigate the measurement error;

4. the same effect is achieved if the thermal resistance of the heat flow probe is taken into account, although with less relevant improvement.

All these observations show that heat flux density measurement, when the probe is installed on the surface of a rough material exchanging heat by convection and radiation, is inherently prone to errors. Therefore, despite the issues discussed, the analytical model reliability is confirmed.

This work will be further developed: first, the analytical model will be expanded in order to handle multilayer components, and then experimentally validated. Then, the analytical model of multilayer Breathing Walls will be used to understand the dynamic behavior of Breathing Walls and possibly derive the key dynamic properties. On the other end, the effort will be focused on studying the convective heat transfer coefficient for Breathing Walls, both on free surfaces and in cavity.

\section{Funding}

This research did not receive any specific grant from funding agencies in the public, commercial, or not-forprofit sectors.

\section{References}

[1] EU Commission and Parliament. Directive 2002/91/EU of the European Parliament and of the Council of 16 December 2002 on the Energy Performance of Buildings.

[2] EU Commission and Parliament, Directive 2010/31/EU of the European Parliament and of the Council of 19 May 2010 on the Energy Performance of Buildings (EPBD Recast).

[3] F. Ascione, Energy conservation and renewable technologies for buildings to face the impact of the climate change and minimize the use of cooling. Solar Energy 154 (2017) 34-100.

[4] B. Park, W.V. Srubar III, M. Krarti, Energy performance analysis of variable thermal resistance envelopes in residential buildings. Energy and Buildings 103 (2015) 317-325.

[5] K. Menyhart, M. Krarti, Potential energy savings from deployment of Dynamic Insulation Materials for US residential buildings. Building and Environment 114 (2017) 203-218.

[6] V. Shekar, M. Krarti, Control strategies for dynamic insulation materials applied to commercial buildings. Energy and Buildings 154 (2017) 305-320.

[7] E. Elsarrag, Y. Al-Horr, M.S. Imbabi, Improving building fabric energy efficiency in hot-humid climates using dynamic insulation. Building Simulation 5 (2012) 127-134.

[8] B.J. Taylor, D.A. Cawthorne, M.S. Imbabi, Analytical Investigation of the Steady-State Behaviour of Dynamic and Diffusive Building Envelopes. Building and Environment 31 (1996) 519525.

[9] J.T. Brunsell, The Performance of Dynamic Insulation in Two Residential Buildings. Air Infiltration Review 16 (1995) 377382.

[10] B.J. Taylor, M.S. Imbabi, The application of dynamic insulation in buildings. Building and Environment 15 (1998) 377-382.

[11] A. Alongi, A. Angelotti, L. Mazzarella, Measuring a Breathing Wall's effectiveness and dynamic behaviour. Indoor and Built Environment (2019) DOI: 10.1177/1420326X19836457.

[12] A. Alongi, A. Angelotti, L. Mazzarella, Experimental investigation of the steady state behaviour of Breathing Walls by means of a novel laboratory apparatus. Building and Environment 123 (2017) 415-426. 
[13] A. Alongi, A. Angelotti, L. Mazzarella, Analytical modelling of Breathing Walls: experimental verification by means of the Dual Air Vented Thermal Box lab facility. Energy Procedia 140 (2017) 36-47.

[14] A. Yaegashi, K. Hiyama, S. Kato, J. Tezuka, S. Nikawa, Thermal Performance Evaluation of a Dynamic Insulation Technology Applied to a Timber Framework House in a Real Environment. Journal of Asian Architecture and Building Engineering 14 (2015) 213-218.

[15] G. Gan, Numerical evaluation of thermal comfort in rooms with dynamic insulation. Building and Environment 35 (2000) 445453.

[16] E. Di Giuseppe, M. D’Orazio, C. Di Perna, Thermal and filtration performance assessment of a dynamic insulation system. Energy Procedia 78 (2015) 513-518.

[17] S. Craig, J. Grinham, Breathing walls: The design of porous materials for heat exchange and decentralized ventilation. Energy and Buildings 149 (2017) 246-259.

[18] J. Wang, Q. Du, C. Zhang, X. Xu, W. Gang, Mechanism and preliminary performance analysis of exhaust air insulation for building envelope wall. Energy and Buildings 173 (2018) 516529.

[19] A. Dimoudi, A. Androutsopoulos, S. Lykoudis, Experimental work on a linked, dynamic and ventilated wall component. Energy and Buildings 36 (2004) 443-453.

[20] F. Ascione, N. Bianco, C. De Stasio, G.M. Mauro, G.P. Vanoli, Dynamic insulation of the building envelope: Numerical modeling under transient conditions and coupling with nocturnal free cooling. Applied Thermal Engineering 84 (2015) 1-14.

[21] S. Murata, T. Tsukidate, A. Fukushima, M.Abuku, H. Watanabe, A. Ogawa, Periodic Alternation between Intake and Exhaust of Air in Dynamic Insulation: Measurements of Heat and Moisture Recovery Efficiency. Energy Procedia 78 (2015) 531-536.

[22] B.J. Taylor, M.S. Imbabi, The effect of air film thermal resistance on the behaviour of dynamic insulation. Building and Environment 32 (1997) 397-404.

[23] A. Alongi, A. Angelotti, L. Mazzarella, Experimental validation of a finite difference algorithm to simulate Breathing Wall components. Proceedings of Building Simulation 2019, 2-4 Sept. 2019, Rome, Italy (in press).

[24] ISO 13786, Thermal performance of building components. Dynamic thermal characteristics. Calculation methods. Ente Italiano di Unificazione, Milano, 2017.

[25] H.S. Carslaw, J.C. Jaeger, Conduction of heat in solids. $2^{\text {nd }}$ edition. London, Oxford University Press (1959).

[26] M. Krarti, Effect of air flow on heat transfer in walls. Journal of Solar Energy Engineering 116 (1994) 35-42.

[27] M. Kaviany, Principle of Heat Transfer in Porous Media. $2^{\text {nd }}$ edition. New York, Springer (1995).

[28] A. Alongi, L. Mazzarella, Characterization of Fibrous Insulating Materials in their Application in Dynamic Insulation Technology. Energy Procedia 78 (2015) 537-542.

[29] A. Alongi, L. Mazzarella, The Dual Air Vented Thermal Box: A Laboratory Apparatus to Test Air Permeable Building Envelope Technologies. Energy Procedia 78 (2015) 1543-1548.

[30] B.J. Taylor, R. Webster, M.S. Imbabi, The building envelope as an air filter. Building and Environment 34 (1999) 353-361.

[31] J.M. Wong, F.P. Glasser, M.S. Imbabi, Evaluation of thermal conductivity in air permeable concrete for dynamic breathing wall construction. Cement \& Concrete Composites 29 (2007) 647-655.

[32] Y. He, Rapid thermal conductivity measurement with a hot disk sensor - part 1. Theoretical considerations. Thermochimica Acta 436 (2005) 122-129.

[33] D.A. Nield, A. Bejan, Convection in Porous Media. $3^{r d}$ edition.
USA, Springer (2000).

\section{Appendix A. Real and Imaginary part of temper- ature and conductive heat flux equa- tions}

The fluctuating component of the temperature distribution can be calculated according to Eq.11. Its module $\Delta \mathrm{T}(\mathrm{x})$ and its phase $\phi$ have to be defined with respect to $\widetilde{\vartheta}(x)$ :

$$
\left\{\begin{array}{l}
\Delta T(x)=|\widetilde{\vartheta}(x)|=\sqrt{\mathfrak{R}[\widetilde{\vartheta}(x)]^{2}+\mathfrak{J}[\widetilde{\vartheta}(x)]^{2}} \\
\phi=\arctan (\mathfrak{J}[\widetilde{\vartheta}(x)] / \mathfrak{R}[\widetilde{\vartheta}(x)])
\end{array}\right.
$$

Once these two quantities are calculated, they can be combined to obtain $\widetilde{\vartheta}(x, t)$ :

$$
\begin{aligned}
\widetilde{\vartheta}(x, t) & =\left(\Delta T(x) e^{i \phi}\right) e^{i \omega t}= \\
= & \Delta T(x) \cdot[\cos (\omega t+\phi)+i \cdot \sin (\omega t+\phi)]
\end{aligned}
$$

Therefore, the solution for $\widetilde{T}$ is either the real part of $\widetilde{\vartheta}(x, t)$ (boundary conditions defined using the cosine function) or its imaginary part (boundary conditions defined using the sine function). In order proceed with the calculation, it is essential to divide Eq. (16) and (18) into their real and imaginary part. The $\widetilde{\beta}$ coefficient has been manipulated as:

$$
\widetilde{\beta}=\sqrt{\frac{P e^{2}}{4 L^{2}}+\frac{i \omega}{\alpha_{w}}}=a_{\beta}+i b_{\beta}
$$

with:

$$
\frac{P e^{2}}{4 L^{2}}=\delta^{2} \text { and } \frac{\omega}{\alpha_{w}}=\xi^{2}
$$

This process leads to the following values for the real and imaginary part of the $\widetilde{\beta}$ coefficient:

$$
\left\{\begin{array}{l}
a_{\beta}= \pm \sqrt{\frac{\delta^{2}}{2}+\frac{1}{2} \sqrt{\delta^{4}+\xi^{4}}} \\
b_{\beta}= \pm \sqrt{-\frac{\delta^{2}}{2}+\frac{1}{2} \sqrt{\delta^{4}+\xi^{4}}}
\end{array}\right.
$$

Both Eq. (16) and (18) can now be manipulated, in order to make their respective real and imaginary parts explicit: 


$$
\begin{gathered}
\widetilde{\vartheta}(x)=\left\{\frac{e^{\frac{P e}{2} L}}{2} \frac{\cosh \left[a_{\beta}(2 L-x)\right] \cos \left(b_{\beta} x\right)-\cosh \left(a_{\beta} x\right) \cos \left[b_{\beta}(2 L-x)\right]}{\sinh ^{2}\left(a_{\beta} L\right)+\sin ^{2}\left(b_{\beta} L\right)} \widetilde{\vartheta}_{0}+\right. \\
\left.+\frac{e^{\frac{P e}{2}\left(\frac{x}{L}-1\right)}}{2} \frac{\cosh \left[a_{\beta}(L+x)\right] \cos \left[b_{\beta}(L-x)\right]-\cosh \left[a_{\beta}(L-x)\right] \cos \left[b_{\beta}(L+x)\right]}{\sinh ^{2}\left(a_{\beta} L\right)+\sin ^{2}\left(b_{\beta} L\right)} \widetilde{\vartheta}_{L}\right\}+ \\
+i\left\{\frac{e^{\frac{P e}{2} \frac{x}{L}}}{2} \frac{\sinh \left(a_{\beta} x\right) \sin \left[b_{\beta}(2 L-x)\right]-\sinh \left[a_{\beta}(2 L-x)\right] \sin \left(b_{\beta} x\right)}{\sinh ^{2}\left(a_{\beta} L\right)+\sin ^{2}\left(b_{\beta} L\right)} \widetilde{\vartheta}_{0}+\right. \\
\left.+\frac{e^{\frac{P e}{2}\left(\frac{x}{L}-1\right)}}{2} \frac{\sinh \left[a_{\beta}(L-x)\right] \sin \left[b_{\beta}(L+x)\right]-\sinh \left[a_{\beta}(L+x)\right] \sin \left[b_{\beta}(L-x)\right]}{\sinh ^{2}\left(a_{\beta} L\right)+\sin ^{2}\left(b_{\beta} L\right)} \widetilde{\vartheta}_{L}\right\}
\end{gathered}
$$

$$
\begin{aligned}
& \widetilde{\varphi}_{c d}(x)=-\lambda_{w} \frac{e^{\frac{P_{e} x}{2}}}{2}\left\{\frac{P e}{2 L} \frac{\cosh \left[a_{\beta}(2 L-x)\right] \cos \left(b_{\beta} x\right)-\cosh \left(a_{\beta} x\right) \cos \left[b_{\beta}(2 L-x)\right]}{\sinh ^{2}\left(a_{\beta} L\right)+\sin ^{2}\left(b_{\beta} L\right)}+\right. \\
& -a_{\beta} \frac{\sinh \left[a_{\beta}(2 L-x)\right] \cos \left(b_{\beta} x\right)+\sinh \left(a_{\beta} x\right) \cos \left[b_{\beta}(2 L-x)\right]}{\sinh ^{2}\left(a_{\beta} L\right)+\sin ^{2}\left(b_{\beta} L\right)}+ \\
& \left.-b_{\beta} \frac{\cosh \left[a_{\beta}(2 L-x)\right] \sin \left(b_{\beta} x\right)+\cosh \left(a_{\beta} x\right) \sin \left[b_{\beta}(2 L-x)\right]}{\sinh ^{2}\left(a_{\beta} L\right)+\sin ^{2}\left(b_{\beta} L\right)}\right\} \widetilde{\vartheta}_{0}+ \\
& -\lambda_{w} \frac{e^{\frac{P e}{2}\left(\frac{x}{L}-1\right)}}{2}\left\{\frac{P e}{2 L} \frac{\cosh \left[a_{\beta}(L+x)\right] \cos \left[b_{\beta}(L-x)\right]-\cosh \left[a_{\beta}(L-x)\right] \cos \left[b_{\beta}(L+x)\right]}{\sinh ^{2}\left(a_{\beta} L\right)+\sin ^{2}\left(b_{\beta} L\right)}+\right. \\
& +a_{\beta} \frac{\sinh \left[a_{\beta}(L+x)\right] \cos \left[b_{\beta}(L-x)\right]+\sinh \left[a_{\beta}(L-x)\right] \cos \left[b_{\beta}(L+x)\right]}{\sinh ^{2}\left(a_{\beta} L\right)+\sin ^{2}\left(b_{\beta} L\right)}+ \\
& \left.+b_{\beta} \frac{\cosh \left[a_{\beta}(L+x)\right] \sin \left[b_{\beta}(L-x)\right]+\cosh \left[a_{\beta}(L-x)\right] \sin \left[b_{\beta}(L+x)\right]}{\sinh ^{2}\left(a_{\beta} L\right)+\sin ^{2}\left(b_{\beta} L\right)}\right\} \widetilde{\vartheta}_{L^{+}} \\
& -i \lambda_{w} \frac{e^{\frac{P_{e}}{2} \frac{x}{L}}}{2}\left\{\frac{P e}{2 L} \frac{\sinh \left(a_{\beta} x\right) \sin \left[b_{\beta}(2 L-x)\right]-\sinh \left[a_{\beta}(2 L-x)\right] \sin \left(b_{\beta} x\right)}{\sinh ^{2}\left(a_{\beta} L\right)+\sin ^{2}\left(b_{\beta} L\right)}+\right. \\
& +a_{\beta} \frac{\cosh \left[a_{\beta}(2 L-x)\right] \sin \left(b_{\beta} x\right)+\cosh \left(a_{\beta} x\right) \sin \left[b_{\beta}(2 L-x)\right]}{\sinh ^{2}\left(a_{\beta} L\right)+\sin ^{2}\left(b_{\beta} L\right)}+ \\
& \left.-b_{\beta} \frac{\sinh \left[a_{\beta}(2 L-x)\right] \cos \left(b_{\beta} x\right)+\sinh \left(a_{\beta} x\right) \cos \left[b_{\beta}(2 L-x)\right]}{\sinh ^{2}\left(a_{\beta} L\right)+\sin ^{2}\left(b_{\beta} L\right)}\right\} \widetilde{\vartheta}_{0}+ \\
& -i \lambda_{w} \frac{e^{\frac{P e}{2}\left(\frac{x}{L}-1\right)}}{2}\left\{\frac{P e}{2 L} \frac{\sinh \left[a_{\beta}(L-x)\right] \sin \left[b_{\beta}(L+x)\right]-\sinh \left[a_{\beta}(L+x)\right] \sin \left[b_{\beta}(L-x)\right]}{\sinh ^{2}\left(a_{\beta} L\right)+\sin ^{2}\left(b_{\beta} L\right)}+\right. \\
& -a_{\beta} \frac{\cosh \left[a_{\beta}(L+x)\right] \sin \left[b_{\beta}(L-x)\right]+\cosh \left[a_{\beta}(L-x)\right] \sin \left[b_{\beta}(L+x)\right]}{\sinh ^{2}\left(a_{\beta} L\right)+\sin ^{2}\left(b_{\beta} L\right)}+ \\
& \left.+b_{\beta} \frac{\sinh \left[a_{\beta}(L+x)\right] \cos \left[b_{\beta}(L-x)\right]+\sinh \left[a_{\beta}(L-x)\right] \cos \left[b_{\beta}(L+x)\right]}{\sinh ^{2}\left(a_{\beta} L\right)+\sin ^{2}\left(b_{\beta} L\right)}\right\} \widetilde{\vartheta}_{L}
\end{aligned}
$$

